\title{
Current insights into the innate immune system dysfunction in irritable bowel syndrome
}

\author{
Nikolaos Lazaridis, Georgios Germanidis \\ AHEPA University General Hospital of Thessaloniki, Thessaloniki, Greece
}

\section{Abstract}

\section{Introduction}

Irritable bowel syndrome (IBS) is a common functional gastrointestinal disease characterized by recurrent abdominal pain that is associated with defecation or an alteration in bowel habits. IBS can be classified into four subtypes based on the predominant stool pattern (IBS with diarrhea [IBS-D], IBS with constipation [IBS-C], IBS with mixed bowel habits [IBS-M], and unclassified IBS) [1].

IBS is a very common diagnosis worldwide, with a calculated prevalence of $10-15 \%$, although there are variations depending

Gastroenterology Department, AHEPA University General Hospital of Thessaloniki, Thessaloniki, Greece

Conflict of Interest: None

Correspondence to: Nikolaos Lazaridis, AHEPA University Hospital of Thessaloniki, Stylponos Kyriakidi 1, 54636 Thessaloniki, Greece, e-mail: nikos.lazaridis@gmail.com

Received 18 August 2017; accepted 22 November 2017; published online 18 January 2018

DOI: https://doi.org/10.20524/aog.2018.0229 on the country and the criteria used to define IBS [2-4]. There is a slight predominance of female patients and the onset of symptoms usually occurs at a young age [3]. Over the last years, recognition of IBS has improved, together with the increasing credibility of the diagnostic criteria developed by the Rome consensus [5,6]; however, clinical experience is still broadly exercised by physicians [7].

The socioeconomic impact of IBS is large across continents. Annual direct medical costs in the USA alone vary from 2-10 billion US dollars, while estimates of indirect medical costs, as patients are frequently absent from work, are even greater $[8,9]$. Therapeutic interventions are still ineffective and unable to relieve the burden on patients' quality of life [10].

The pathophysiology of the syndrome is poorly understood, while a number of possible mechanisms, such as visceral hypersensitivity, abnormal gut motility, and irregular braingut interaction, are implicated in its development (Fig. 1) [11]. Chronic low-grade intestinal mucosal inflammation is another of these potential etiological factors. A number of studies have documented alterations in MC, T lymphocytes, B lymphocytes, and cytokine concentrations in the colonic mucosa or the systemic circulation in IBS patients compared with healthy 


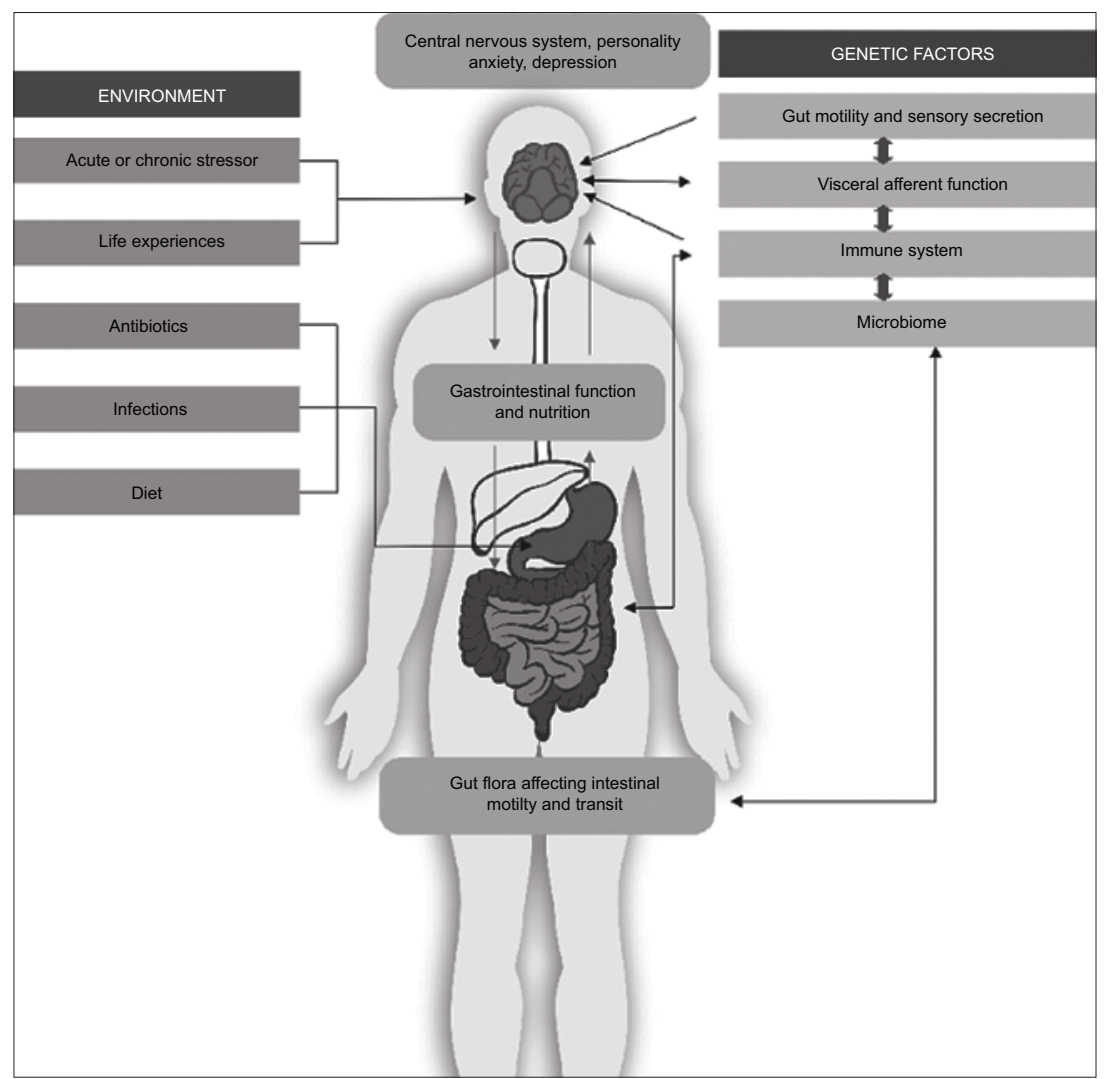

Figure 1 Schematic illustration of the putative factors involved in the pathogenesis of irritable bowel syndrome (IBS). Multiple mechanisms interact in the development of IBS symptoms in each individual. Both environmental parameters and genes could potentially contribute to the manifestation of IBS

controls [12]. This review summarizes the current knowledge regarding the role of immune activation in the pathogenesis and the development of IBS.

\section{Low-grade inflammation}

IBS was regarded as an exclusively functional disorder, but recent studies have demonstrated evidence oflow-grade mucosal inflammation in some IBS patients. Mechanisms associated with post-infectious alterations [13], dysfunctional epithelial permeability [14], abnormalities in gut microbiota [15], and elevated stress levels [16] can enhance or stimulate abnormal immune responses. A combination of low-grade inflammation of the intestinal mucosa with impaired bowel motility and visceral sensitivity could explain the underlying etiology and pathology of IBS.

The hypothesis of the importance of immune dysfunction in the pathogenesis of IBS was initially based on the observation that IBS symptoms developed following episodes of infectious gastroenteritis elicited by bacteria, viruses or parasites. This syndrome was defined as post-infectious IBS (PI-IBS) [17]. Several studies verified the association of infectious enteritis and the risk of developing IBS, and a meta-analysis reported an estimated sevenfold increase compared with the controls groups [18]. Researchers reported that female sex and young age, anxiety, depression and a protracted period of the initial infection with fever, are risk factors for the development of PI-IBS $[13,19]$. Moreover, dysbiotic microbiota caused by an infectious gastroenteritis could promote inflammation and alter the innate immune reaction in PI-IBS patients [20]. Intestinal mucosal biopsies from patients with PI-IBS revealed elevated numbers of immunity cells, such as lymphocytes and MC [21-23]. Notably, patients with PI-IBS also have increased cytokine production compared with healthy controls or compared with patients who have fully recovered from infectious enteritis [24,25].

Additionally, IBS and inflammatory bowel disease (IBD) studies have revealed overlapping pathways between the two diseases, such as dysregulated immune activation and abnormalities of the enteric nerve function [26,27]. IBD patients in clinical remission report IBS-like symptoms combined with impaired quality of life and psychological symptoms [28]. Likewise, an increased number of patients with celiac disease and microscopic colitis develop symptoms resembling those of IBS compared with controls [29,30]. Furthermore, data suggest that IBS-like symptoms precede the diagnosis of IBD [31]. The overlap of symptoms in IBS and IBD could thus be explained by similarities in their etiology 
and the underlying mechanisms. Specifically, the presence of low-grade mucosal inflammation and mild immune activation in IBS patients may account for the common clinical features also present in patients with IBD.

Molecular genetics studies have indicated a positive association between IBS pathophysiology and genetic factors, although these results were not always replicated [32]. Numerous gene variants related to serotonin metabolism, intestinal barrier and visceral perception were examined. Furthermore, single nucleotide polymorphisms (SNPs) in the TNFSF15 gene were investigated regarding their potential contribution to immune modulation, low-grade inflammation and cytokine production [33]. Nevertheless, one meta-analysis identified only a moderate association between rs4263839 TNFSF15 and IBS-C patients, while none of the other 16 SNPs studied showed any relevance with IBS symptom phenotypes [34].

Emerging data from experimental studies in IBS pathogenesis are inconclusive, which probably reflects the heterogeneity of the disorder and the differences between the syndrome subgroups. Yet, preliminary results provide evidence for a link between gut microbiota and host immune response in the development of IBS.

\section{Innate immune activation}

Low-grade inflammation in IBS patients can be assessed by alterations in the immune cell populations and mediators. The role of MC, monocytes, neutrophils, natural killer (NK) cells and eosinophils has been evaluated. Cytokine production and activity has been investigated in numerous studies, along with other proinflammatory mediators. Earlier studies mainly focused on systemic immune activation through the role of immune cells and their mediators in serum and plasma of IBS patients. More recent studies have also examined mucosal samples as a more accurate indicator of immune activity and have identified mucosal infiltration of immunocytes and elevated proinflammatory cytokines levels in IBS patients $[35,36]$. Results from biopsy samples might provide a better understanding of the relevant mechanisms in IBS pathophysiology and help identify potential disease indicators [37].

The potential relationship between innate immune dysregulation in IBS patients and perceived symptoms has also been explored [38]. In a recent study, tumor necrosis factor (TNF)- $\alpha$ and interleukin (IL)-17 serum levels were correlated with discomfort and severity of symptoms in IBS patients [39]. Nevertheless, measurement of cytokine levels in the serum and intestinal mucosa in another study with 144 IBS patients and 42 healthy controls provided no correlation between the overall symptom severity and the cytokine expression, although IL-6 and IL-8 levels were slightly increased in the IBS group [40]. Several studies imply this imperceptible link between lowgrade immune activity and IBS symptoms [41-43], raising the hope of future therapeutic possibilities for IBS patients. So far, anti-inflammatory therapies have proven unsuccessful in IBS patients, but better selected subgroups might indeed benefit from these type of treatments $[44,45]$.

\section{MC and their mediators}

MC are long-lived granulated cells that circulate in the blood and are also found in tissues; they can release tryptase, histamine and chymase as a result of their activation $[46,47]$. The involvement of MC in the pathogenesis of IBS is attributed to their mediators, which can alter enteric nerve and motor function [48]. MC counts and density vary among different studies and among different segments of the intestine, though the majority of studies report greater numbers and volume in IBS patients compared with healthy controls (Table 1) [23,41,49-65].

Indications for the role of MC in IBS pathogenesis were firstly considered when elevated number of MC were reported in mucosal biopsies of the terminal ileum and then confirmed in several studies, mainly in patients with IBS-D or PI-IBS $[23,58,60,61]$. Interestingly, one study with 50 predominantly female IBS patients (Rome III criteria) reported no differences in MC numbers between controls and all IBS patients, independently of bowel habit subtype [50]. Furthermore, a recent assessment of 66 Rome II IBS patients and 20 controls found that the former group had lower numbers of MC in biopsies of the descending colon [52]. In addition, a Spanish group found similar MC numbers in jejunal biopsies in 49 Rome III IBS-D patients compared with controls. Nevertheless, the MC density was higher in IBS patients and the proximity of MC to plasma cells was significantly lower in the jejunal mucosa [62].

Conflicting data about MC counts could be of little importance, because the increased presence of $\mathrm{MC}$ is not a prerequisite for inflammation. The activation and degranulation of MC appear to correlate with the presentation of IBS. In addition, the proximity of MC to intestinal nerves is considered to be directly associated with the presentation and severity of IBS symptoms $[55,66]$, although not all studies have confirmed the proximity of MC and nerve fibers [67]. MC activation has been associated with structural changes and thus dysfunction in the apical junctional complex integrity in jejunal mucosa, leading to motor and intestinal barrier dysfunction in IBS-D patients $[49,64]$. Histamine and tryptase as MC mediators can alter nociceptive visceral sensory nerve function and cause stimulation and hypersensitivity $[68,69]$. Furthermore tryptase may downregulate the expression of junctional adhesion molecule-A in vitro and, therefore, increase epithelial permeability in IBS [70]. Augmented secretion of tryptase and histamine has been documented in duodenal, colon and rectum biopsies in some IBS studies [54,63,68,71-73]. However, rectal biopsies from 29 IBS patients and 22 healthy controls revealed no difference in tryptase release, while MC numbers were smaller in IBS patients. In the same study, histamine release in all patients with IBS was significantly increased compared with healthy volunteers. Administration of ketotifen, an MC stabilizer, did not affect the release of 
Table 1 Mast cell counts in studies with at least 50 participants (IBS and controls)

\begin{tabular}{|c|c|c|c|c|c|c|}
\hline Author & $\begin{array}{l}\text { Number of } \\
\text { participants } \\
\text { (IBS: } \\
\text { controls) }\end{array}$ & $\begin{array}{l}\text { Diagnostic } \\
\text { criteria }\end{array}$ & Site of biopsy & Results & Subtype & Patients' sex \\
\hline $\begin{array}{l}\text { Chadwick } \\
2002[41]\end{array}$ & $77: 28$ & Rome I & $\begin{array}{l}\text { Ascending, transverse, } \\
\text { descending colon and } \\
\text { rectum }\end{array}$ & Increased numbers & $\begin{array}{l}35 \text { IBS-D } \\
10 \text { IBS-C } \\
20 \text { IBS-M } \\
4 \text { IBS-U }\end{array}$ & $\begin{array}{l}53 \text { female } \\
16 \text { male }\end{array}$ \\
\hline $\begin{array}{l}\text { Dunlop } \\
2003[145]\end{array}$ & $28: 34$ & Rome I & Rectum & No difference in numbers & 28 PI-IBS & $\begin{array}{l}17 \text { female } \\
11 \text { male }\end{array}$ \\
\hline $\begin{array}{l}\text { Dunlop } \\
2003[146]\end{array}$ & $75: 36$ & Rome II & Rectum & $\begin{array}{l}\text { Increased numbers in } \\
\text { non PI-IBS (a trend to be } \\
\text { elevated } P=0.054)\end{array}$ & $\begin{array}{l}23 \text { PI-IBS } \\
52 \text { non PI-IBS }\end{array}$ & $\begin{array}{l}53 \text { female } \\
22 \text { male }\end{array}$ \\
\hline $\begin{array}{l}\text { Wang } \\
2004[57]\end{array}$ & $56: 12$ & Rome II & $\begin{array}{l}\text { Terminal ileum and } \\
\text { rectosigmoid junction }\end{array}$ & $\begin{array}{l}\text { Increased numbers only at } \\
\text { the terminal ileum }\end{array}$ & 56 IBS-D & $\begin{array}{l}31 \text { female } \\
25 \text { male }\end{array}$ \\
\hline $\begin{array}{l}\text { Barbara } \\
2004[55]\end{array}$ & $44: 22$ & Rome II & Descending colon & $\begin{array}{l}\text { Increased numbers } \\
\text { Increased activation } \\
\text { (degranulating mast cells) }\end{array}$ & $\begin{array}{l}22 \text { IBS-D } \\
22 \text { IBS-C }\end{array}$ & $\begin{array}{l}31 \text { female } \\
13 \text { male }\end{array}$ \\
\hline $\begin{array}{l}\text { Wang } \\
2007[56]\end{array}$ & $38: 20$ & Rome III & $\begin{array}{l}\text { Terminal ileum, } \\
\text { duodenum and } \\
\text { jejunum }\end{array}$ & $\begin{array}{l}\text { Increased numbers only at } \\
\text { the terminal ileum }\end{array}$ & $\begin{array}{l}20 \text { IBS-D } \\
18 \text { IBS-C }\end{array}$ & $\begin{array}{l}21 \text { female } \\
17 \text { male }\end{array}$ \\
\hline $\begin{array}{l}\text { Piche } \\
2008 \text { [79] }\end{array}$ & $50: 21$ & Rome II & Cecum & Increased numbers & $\begin{array}{l}21 \text { IBS-D } \\
29 \text { IBS-C }\end{array}$ & $\begin{array}{l}41 \text { female } \\
9 \text { male }\end{array}$ \\
\hline $\begin{array}{l}\text { Cremon } \\
2009[51]\end{array}$ & $48: 24$ & Rome II & Descending colon & Increased numbers & $\begin{array}{l}27 \text { IBS-D } \\
21 \text { IBS-C }\end{array}$ & $\begin{array}{l}35 \text { female } \\
13 \text { male }\end{array}$ \\
\hline $\begin{array}{l}\text { Walker } \\
2009[77]\end{array}$ & $41: 48$ & $\begin{array}{l}\text { Sweden } \\
\text { questionnaire } \\
\text { similar to } \\
\text { Rome I }\end{array}$ & Duodenum & $\begin{array}{l}\text { Numerically increased cell } \\
\text { counts }\end{array}$ & $\begin{array}{l}20 \text { IBS-D } \\
21 \text { IBS-C }\end{array}$ & $\begin{array}{l}20 \text { female } \\
21 \text { male }\end{array}$ \\
\hline $\begin{array}{l}\text { Goral } \\
2010[60]\end{array}$ & $72: 50$ & Rome III & Cecum and rectum & Increased numbers & $\begin{array}{l}40 \text { IBS-D } \\
32 \text { IBS-C }\end{array}$ & \\
\hline $\begin{array}{l}\text { Bhuiyan } \\
2010[147]\end{array}$ & $50: 10$ & --- & Sigmoid colon & Increased numbers & $\begin{array}{l}18 \text { PI-IBS } \\
32 \text { non PI-IBS }\end{array}$ & \\
\hline $\begin{array}{l}\text { Chang } \\
2012[65]\end{array}$ & $45: 41$ & Rome II & Sigmoid colon & No difference in numbers & $\begin{array}{l}16 \text { IBS-C } \\
15 \text { IBS-D } \\
14 \text { IBS-M }\end{array}$ & $\begin{array}{l}26 \text { female } \\
19 \text { male }\end{array}$ \\
\hline $\begin{array}{l}\text { Braak } \\
2012[52]\end{array}$ & $66: 20$ & Rome II & $\begin{array}{l}\text { Ascending and } \\
\text { descending colon }\end{array}$ & Decreased numbers & $\begin{array}{l}15 \text { IBS-D } \\
15 \text { IBS-C } \\
36 \text { IBS-A }\end{array}$ & $\begin{array}{l}49 \text { female } \\
17 \text { male }\end{array}$ \\
\hline $\begin{array}{l}\text { De Silva } \\
2012[61]\end{array}$ & $49: 14$ & Rome III & $\begin{array}{l}\text { Ileum, cecum, } \\
\text { ascending, transverse, } \\
\text { descending colon and } \\
\text { rectum }\end{array}$ & $\begin{array}{l}\text { Increased numbers in all } \\
\text { sites apart from transverse } \\
\text { colon }\end{array}$ & 49 IBS-D & $\begin{array}{l}13 \text { female } \\
36 \text { male }\end{array}$ \\
\hline $\begin{array}{l}\text { Martinez } \\
2013[49]\end{array}$ & $45: 30$ & Rome II & Jejunum & $\begin{array}{l}\text { Increased numbers and } \\
\text { activation }\end{array}$ & 45 IBS-D & $\begin{array}{l}34 \text { female } \\
11 \text { male }\end{array}$ \\
\hline $\begin{array}{l}\text { El-Salhy } \\
2013[50]\end{array}$ & $50: 27$ & Rome III & Colon and rectum & $\begin{array}{l}\text { No difference in numbers } \\
\text { nor density }\end{array}$ & $\begin{array}{l}30 \text { IBS-D } \\
20 \text { IBS-C }\end{array}$ & $\begin{array}{l}42 \text { female } \\
8 \text { male }\end{array}$ \\
\hline $\begin{array}{l}\text { Vicario } \\
2015 \text { [62] }\end{array}$ & $49: 30$ & Rome III & Jejunum & $\begin{array}{l}\text { No difference in numbers } \\
\text { Increased density }\end{array}$ & 49 IBS-D & $\begin{array}{l}33 \text { female } \\
16 \text { male }\end{array}$ \\
\hline
\end{tabular}

IBS, irritable bowel syndrome; IBS-C, constipation predominant; IBS-D, diarrhea predominant; IBS-M, mixed; IBS-U, unsubtyped; IBS-A, with alternating stool pattern; PI-IBS, post-infectious

either histamine or tryptase, but effectively ameliorated visceral hypersensitivity and IBS symptoms [72]. Contrariwise, ebastine, an antagonist of histamine receptor $\mathrm{H} 1$, improved both visceral hypersensitivity and symptom discomfort in a proof-of-principle pilot study with 55 Rome III IBS patients, compared with placebo [69]. 


\section{Eosinophils, basophils}

Eosinophils are potent immune cells found in the intestinal mucosa; they participate in host immunity and maintain homeostasis of the intestinal barrier. The exact etiology of eosinophil migration from the blood to the mucosa is unclear, but seems to be associated with inflammation [74,75]. A recent study found increased eosinophil counts in 23 of 42 IBS Rome II patients in colonic biopsies [76], while the number of eosinophil cells was significantly higher in the cecum and in the right colon of 49 IBS-D patients from Sri Lanka [61]. However, other researchers found no differences in eosinophils counts in the duodenum [77], jejunum [59,64], ileum [78], cecum [78-80], ascending and descending colon, and rectum $[78,80]$. Additionally, no alterations in eosinophil numbers in rectal biopsies were observed in children with IBS [67]. Eosinophils can secrete cytotoxic granule cationic proteins implicated in tissue damage [74]. Studies in IBS patients revealed no difference in eosinophil cationic protein (ECP) [81] or eosinophil protein $\mathrm{X}$ (EPX) [82] compared with controls. Measurements of fecal EPX also presented inconclusive results $[83,84]$, while positive skin prick tests and high blood immunoglobulin E and ECP values were more common in IBS patients [85].

The role of basophils is scarcely investigated in IBS patients. A recent study of non-celiac wheat sensitivity utilized IBS Rome II patients as the control group and assessed in vitro basophil activation with a flow cytometric test. Basophil activation was less pronounced in the blood samples of IBS patients [86,87]. Likewise, a Turkish study documented no difference in systemic basophil counts between 30 IBS Rome III patients and 30 controls [88].

\section{NK cells}

There are only a few data concerning the role of NK cells in IBS. A few studies with small groups of IBS patients measured NK cell numbers in blood samples and found them to be decreased or unaltered [89-92]. Another large study with 77 IBS patients and 28 controls reported no differences in lamina propria NK cell numbers, during histologic assessment of colon and rectum biopsies [41].

\section{Neutrophils}

Neutrophils are phagocytic cells of the immune system and migrate to the gastrointestinal mucosa when activated during inflammation. In rectal biopsies of children with IBS, no difference in neutrophil numbers was evident compared to healthy controls [67]. Furthermore, in a study of 49 IBS-D patients from Sri Lanka, neutrophil counts were similar to those of controls in biopsies from the ileum, cecum, colon, and rectum [61]. Similar results were derived from multiple cecum, colon and rectum biopsies of IBS Rome I \& II patients in two other studies $[79,80]$. Conversely, in another study a subgroup of IBS patients reported elevated numbers of neutrophils in mucosal biopsies of the colon [41]. Inflammatory mediators of neutrophils, such as myeloperoxidase, human neutrophil lipocalin and lactoferrin, have been measured in stool but results are inconclusive as only one study showed increased myeloperoxidase levels $[81,83,93]$. Neutrophil gelatinaseassociated lipocalin was measured in blood and urine samples with no significant difference between 41 Rome III IBS patients and 82 controls [94]. Finally, fecal lactoferrin, calprotectin and human $\beta$-defensin-2 (HBD-2) were measured in stool specimens of 46 IBS patients and 24 controls. While no difference was evident for lactoferrin and calprotectin, HBD-2 was elevated in the IBS group [95]. HBD-2 has antimicrobial potential [96] and is usually elevated in patients with IBD [97]; it thus provides a further indication of the presence of intestinal inflammation in IBS.

\section{Dendritic cells (DCs)}

Another cell type that has not been thoroughly investigated for its potential involvement in inflammation is DC. Like neutrophils, DCs are phagocytic cells with a key role in both innate and adaptive immunity and promote inflammatory responses to pathogens [98]. Animal studies have highlighted the role of DCs in IBS pathogenesis through induced visceral hypersensitivity and MC activation [99] and prolonged intestinal activation [100]. In addition, DCs may secrete corticotropin-releasing factor that can induce alterations in intestinal motility and visceral hypersensitivity. Two studies with mouse DCs and human peripheral blood monocyte-derived DCs presented increased levels of corticotropin-releasing factor after stimulation by some commensal bacterial strains $[101,102]$. In a Scandinavian study, 10 patients with self-reported food hypersensitivity were recruited and 9 of them tested positive for IBS according to the Rome II criteria. Although DC blood counts were not significantly different from those of the 10 healthy controls, when monocyte-derived DCs from patients were stimulated with lipopolysaccharide (LPS), they produced more IL-10 compared with controls [103].

\section{Cytokines}

Immune cells can produce a number of cytokines involved in the host response and some have proinflammatory actions, while others suppress inflammation. Various studies have investigated systemic and mucosal levels of cytokines in IBS patients. In vitro experiments using peripheral blood mononuclear cell (PBMC) cultures have yielded contradictory results regarding the expression of certain ILs before and after stimulation (Table 2). Secretion of IL-10, an anti-inflammatory cytokine, was found to be depressed [104-106] at baseline, while IL-1 $\beta$ [42], IL-6 [42], IL-8 [106], IL-12 [104] and TNF- $\alpha[42,106,107]$ wereelevated. In somestudies, when PBMCs were stimulated with Escherichia coli LPS, IL-10 expression was reduced $[92,105]$ and IL-6 expression was increased compared with healthy controls [42]. Those results were not always 
6 N. Lazaridis and G. Germanidis

Table 2 Cytokine expression in cell cultures

\begin{tabular}{|c|c|c|c|c|c|c|c|}
\hline Author & $\begin{array}{l}\text { Number of } \\
\text { participants } \\
\text { (IBS: } \\
\text { controls) }\end{array}$ & $\begin{array}{l}\text { Diagnostic } \\
\text { criteria }\end{array}$ & Site & Results & Subtype & Patients' sex & Notes \\
\hline $\begin{array}{l}\text { Elsenbruch } \\
2004 \text { [91] }\end{array}$ & $15: 15$ & Rome I & $\begin{array}{l}\text { Whole blood } \\
\text { cultures }\end{array}$ & $\begin{array}{l}\text { TNF- } \alpha \text { decreased in LPS } \\
\text { stimulated supernatant } \\
\text { IL- } 6 \text { no difference }\end{array}$ & $\begin{array}{l}3 \text { IBS-C } \\
9 \text { IBS-D } \\
3 \text { IBS-M }\end{array}$ & 15 female & \\
\hline $\begin{array}{l}\text { O’Mahony } \\
2005[104]\end{array}$ & $75: 20$ & Rome II & PBMC & $\begin{array}{l}\text { Higher IL-12 and lower } \\
\text { IL-10 levels }\end{array}$ & $\begin{array}{l}26 \% \text { IBS-C } \\
28 \% \text { IBS-D } \\
45 \% \text { IBS-M }\end{array}$ & $\begin{array}{l}48 \text { female } \\
27 \text { male }\end{array}$ & \\
\hline $\begin{array}{l}\text { Liebregts } \\
2007[42]\end{array}$ & $55: 36$ & Rome II & PBMC & $\begin{array}{l}\text { Higher baseline TNF- } \alpha \\
\text { IL-1 } \beta \text {, IL- } 6 \text { overall (in } \\
\text { particular IBS-D patients) } \\
\text { Higher IL- } 6 \text { after } \\
\text { LPS stimulation } \\
\text { overall (TNF- } \alpha \text {, IL-1 } \beta \\
\text { increased in IBS-D) }\end{array}$ & $\begin{array}{l}17 \text { IBS-C } \\
20 \text { IBS-D } \\
18 \text { IBS-M }\end{array}$ & $\begin{array}{l}33 \text { female } \\
22 \text { male }\end{array}$ & \\
\hline $\begin{array}{l}\text { Kindt } \\
2009[92]\end{array}$ & $30: 32$ & Rome II & PBMC & $\begin{array}{l}\text { Reduced stimulated } \\
\text { monocytic IL-12 } \\
\text { expression Borderline } \\
\text { significant decrease in } \\
\text { IL-10 (LPS) }\end{array}$ & & $\begin{array}{l}24 \text { female } \\
6 \text { male }\end{array}$ & $\begin{array}{l}\text { Patients were } \\
\text { significantly older } \\
\text { than control } \\
\text { subjects }\end{array}$ \\
\hline $\begin{array}{l}\text { Ohman } \\
2009[43]\end{array}$ & $74: 30$ & Rome II & PBMC & $\begin{array}{l}\text { IL-1 } \beta \text { increased after } \\
\text { stimulation by anti-CD3/ } \\
\text { CD28. IFN- } \gamma \text {, IL-10 and } \\
\text { IL- } 2 \text { no difference after } \\
\text { stimulation with controls }\end{array}$ & & $\begin{array}{l}52 \text { female } \\
22 \text { male }\end{array}$ & \\
\hline $\begin{array}{l}\text { Hua } \\
2011[109]\end{array}$ & $35: 25$ & Rome II & PBMC & $\begin{array}{l}\text { IL-10 lower levels at } \\
\text { baseline and after LPS } \\
\text { stimulation } \\
\text { IL- } 6 \text { and TNF- } \alpha \text { have } \\
\text { increased levels at } \\
\text { both measurements } \\
\text { but without achieving } \\
\text { statistical significance }\end{array}$ & $\begin{array}{l}7 \text { IBS-C } \\
17 \text { IBS-D } \\
11 \text { IBS-M }\end{array}$ & $\begin{array}{l}15 \text { girls } \\
20 \text { boys }\end{array}$ & Children patients \\
\hline $\begin{array}{l}\text { Ohman } \\
2012 \text { [108] }\end{array}$ & $74: 30$ & Rome II & PBMC & $\begin{array}{l}\text { IL- } 1 \beta \text {, IL-12 and IL-10 } \\
\text { no differences after LPS } \\
\text { stimulation }\end{array}$ & $\begin{array}{l}11 \text { IBS-C } \\
26 \text { IBS-D } \\
37 \text { IBS-M }\end{array}$ & $\begin{array}{l}52 \text { female } \\
22 \text { male }\end{array}$ & \\
\hline $\begin{array}{l}\text { Swan } \\
2013 \text { [107] }\end{array}$ & $55: 26$ & Rome II & PBMC & $\begin{array}{l}\text { IL-10 increased. TNF- } \alpha \\
\text { increased if } 3 \text { outliers were } \\
\text { excluded }\end{array}$ & $\begin{array}{l}18 \text { IBS-C } \\
37 \text { IBS-D }\end{array}$ & $\begin{array}{l}41 \text { female } \\
14 \text { male }\end{array}$ & \\
\hline $\begin{array}{l}\text { Hua } \\
2013 \text { [105] }\end{array}$ & $94: 102$ & Rome II & PBMC & $\begin{array}{l}\text { IL-10 levels decreased at } \\
\text { baseline and after LPS } \\
\text { stimulation }\end{array}$ & $\begin{array}{l}33 \text { IBS-C } \\
32 \text { IBS-D } \\
29 \text { IBS-M }\end{array}$ & $\begin{array}{l}49 \text { female } \\
45 \text { male }\end{array}$ & \\
\hline $\begin{array}{l}\text { Zhen } \\
2015 \text { [106] }\end{array}$ & $42: 20$ & Rome III & RBMC & $\begin{array}{l}\text { IL- } 8 \text { and TNF- } \alpha \\
\text { increased. IL- } 10 \text { decreased }\end{array}$ & 42 IBS-D & $\begin{array}{l}27 \text { female } \\
15 \text { male }\end{array}$ & $\begin{array}{l}\text { IL- } 8 \text { and TNF- } \alpha \\
\text { were positively } \\
\text { correlated with } \\
\text { worse abdominal } \\
\text { symptoms. IL-10 } \\
\text { was negatively } \\
\text { correlated }\end{array}$ \\
\hline
\end{tabular}

IBS, irritable bowel syndrome; IBS-C, constipation predominant; IBS-D, diarrhea predominant; IBS-M, mixed; IL, interleukin; IFN, interferon;

LPS, lipopolysaccharide; PBMC, peripheral blood mononuclear cell; TNF, tumor necrosis factor 
duplicated and secretion of IL-1 $\beta$, IL-12 and IL-10 showed no differences in LPS-stimulated PBMCs of 72 Rome II IBS patients [108]. In addition, PBMCs of patients belonging to the IBS-D subgroup showed a significantly increased release of TNF- $\alpha$ and IL- $1 \beta$ after LPS stimulation [42]. Moreover, antiCD3/CD28-stimulated PBMCs in 74 Rome II patients showed increased IL- $1 \beta$ production, though interferon (IFN) $-\gamma$, IL-2 and IL-10 secretion was not different than controls [43]. In a recent study of 35 children with Rome II IBS, IL-10 levels were elevated both before and after LPS stimulation of PBMCs, while IL- 6 and TNF- $\alpha$ levels were higher at baseline and after stimulation but without achieving statistical significance [109].

The majority of studies report cytokine levels in the systemic circulation but it is evident that there is great discrepancy among the results, possibly attributable to differences in cytokine measurement assays or the timing of specimen collection (Table 3). Nevertheless, most studies found IL-6 and IL- 8 to be elevated in IBS patients [65,92,108,110-116], whereas IL-10 levels were lower or showed no difference compared with healthy controls $[39,65,92,108,110-115,117,118]$. Secretion of TNF- $\alpha$ is frequently reported without differences between patients and controls [65,110-112], but four studies with a large number of participants all reported that IBS patients had higher levels of TNF- $\alpha$ in serum $[39,113,116,117]$. Other cytokines, such as IL-1 $\beta$, IL-2, IL-4, IL-5, IL-12, IL-13 and IFN- $\gamma$, were not measured in many studies, and when they were no differences were reported $[65,108,110,111,118]$. Two studies were published in 2016, each with more than 100 IBS patients. In the first, which was conducted in China and included 102 Rome III patients, the investigators reported higher IL-6 mRNA and lower IL-10 mRNA expression compared with controls. Furthermore, IBS patients with depression had a higher IL-6 level than those without depression [115]. However, in the latter group, which included 144 Rome III patients, no differences were detected in IL-5, IL-6, IL-8, IL-10, IL-12p70, IL-13, IL-17A, TNF or IFN- $\gamma$ serum levels; IL- 6 and IL- 8 were higher and IFN- $\gamma$ lower, but the difference did not reach statistical significance [40]. In addition, a recent study of 90 Rome III IBS patients and 90 healthy controls revealed that IBS patients had higher serum levels of TNF- $\alpha$ and IL-17 and lower IL-10 levels. Moreover, these inflammatory cytokines had a significant positive correlation with the severity of digestive symptoms and were negatively correlated with quality-of-life scores [39]. Interestingly, 100 IBS Rome II patients, with comorbidities that included fibromyalgia, premenstrual dysmorphic disorder and chronic fatigue syndrome, had higher levels of both IL-1 $\beta$

Table 3 Cytokine expression in systemic circulation (serum and plasma)

\begin{tabular}{|c|c|c|c|c|c|c|c|}
\hline Author & $\begin{array}{l}\text { Number of } \\
\text { participants } \\
\text { (IBS: controls) }\end{array}$ & $\begin{array}{l}\text { Diagnostic } \\
\text { criteria }\end{array}$ & Site & Results & Subtype & Patients' sex & Notes \\
\hline Dinan 2006 [112] & $49: 48$ & Rome II & serum & $\begin{array}{l}\text { IL-6, IL-8 } \\
\text { increased. IL-10 } \\
\text { no difference. } \\
\text { TNF- } \alpha \text { no } \\
\text { difference }\end{array}$ & $\begin{array}{l}13 \% \text { IBS-C } \\
47 \% \text { IBS-D } \\
40 \% \text { IBS-M }\end{array}$ & $\begin{array}{l}66 \% \text { female } \\
34 \% \text { male }\end{array}$ & \\
\hline Dinan 2008 [114] & $37: 37$ & Rome II & blood & $\begin{array}{l}\text { IL-6, IL-8 } \\
\text { increased. IL-10 no } \\
\text { difference }\end{array}$ & $\begin{array}{l}5 \text { IBS-C } \\
18 \text { IBS-D } \\
14 \text { IBS-M }\end{array}$ & $\begin{array}{l}24 \text { female } \\
13 \text { male }\end{array}$ & \\
\hline Kindt 2009 [92] & $30: 32$ & Rome II & serum & $\begin{array}{l}\text { No difference in } \\
\text { basal plasma IL-6, } \\
\text { IL-10 }\end{array}$ & & $\begin{array}{l}24 \text { female } \\
6 \text { male }\end{array}$ & $\begin{array}{l}\text { Patients were significantly } \\
\text { older than controls }\end{array}$ \\
\hline Scully 2010 [110] & $21: 54$ & Rome II & plasma & $\begin{array}{l}\text { IL-6, IL-8 } \\
\text { increased. IL-1 } \beta \text {, } \\
\text { IL-10, IL-12p70, } \\
\text { IL-13, TNF- } \alpha \\
\text { and IFN- } \gamma \text { no } \\
\text { difference }\end{array}$ & & & $\begin{array}{l}\text { Plus } 100 \text { female IBS patients } \\
\text { with co-morbidities as } \\
\text { fibromyalgia, premenstrual } \\
\text { dysmorphic disorder and } \\
\text { chronic fatigue syndrome. } \\
\text { The co-morbidities groups } \\
\text { had increased also IL-1 } \beta \\
\text { and TNF- } \alpha \text {. }\end{array}$ \\
\hline $\begin{array}{l}\text { Del Valle-Pinero } \\
2011 \text { [120] }\end{array}$ & $12: 12$ & Rome III & plasma & $\begin{array}{l}\text { CCL-16 protein } \\
\text { increased but } \\
\text { not statistically } \\
\text { significant }\end{array}$ & $\begin{array}{l}4 \text { IBS-C } \\
8 \text { IBS-D }\end{array}$ & $\begin{array}{l}7 \text { female } \\
5 \text { male }\end{array}$ & \\
\hline $\begin{array}{l}\text { McKernan } \\
2011 \text { [111] }\end{array}$ & $30: 30$ & Rome II & plasma & $\begin{array}{l}\text { IL-6, IL-8 } \\
\text { increased. IL-1 } \beta \text {, } \\
\text { IL-2, IL-4, IL-5, } \\
\text { IL-10, IL-12, IL-13, } \\
\text { TNF- } \alpha \text { and IFN- } \gamma \\
\text { no difference }\end{array}$ & $\begin{array}{l}10 \text { IBS-C } \\
9 \text { IBS-D } \\
11 \text { IBS-M }\end{array}$ & $\begin{array}{l}25 \text { female } \\
5 \text { male }\end{array}$ & No PI-IBS \\
\hline
\end{tabular}


Table 3 (Continued)

\begin{tabular}{|c|c|c|c|c|c|c|c|}
\hline Author & $\begin{array}{l}\text { Number of } \\
\text { participants } \\
\text { (IBS: controls) }\end{array}$ & $\begin{array}{l}\text { Diagnostic } \\
\text { criteria }\end{array}$ & Site & Results & Subtype & Patients' sex & Notes \\
\hline $\begin{array}{l}\text { Ohman } \\
2012 \text { [108] }\end{array}$ & $74: 30$ & Rome II & serum & $\begin{array}{l}\text { IL-1 } \beta, \text { IL-6 } \\
\text { and IL-10 no } \\
\text { differences. IL-10 } \\
\text { increased but } \\
\text { without statistical } \\
\text { significance }\end{array}$ & $\begin{array}{l}11 \text { IBS-C } \\
26 \text { IBS-D } \\
37 \text { IBS-M }\end{array}$ & $\begin{array}{l}52 \text { female } \\
22 \text { male }\end{array}$ & \\
\hline Chang 2012 [65] & $39: 34$ & Rome II & serum & $\begin{array}{l}\text { IL-1 } \beta, \text { IL-6, IL-8, } \\
\text { IL-10, IL-12 } \\
\text { and TNF- } \alpha \text { no } \\
\text { differences }\end{array}$ & $\begin{array}{l}35.5 \% \text { IBS-C } \\
33.3 \% \text { IBS-D } \\
31.1 \% \text { IBS-M }\end{array}$ & $\begin{array}{l}22 \text { female } \\
17 \text { male }\end{array}$ & No PI-IBS \\
\hline Rana 2012 [113] & $63: 62$ & Rome II & serum & $\begin{array}{l}\text { IL- } 6 \text { and TNF- } \alpha \\
\text { increased. IL- } 10 \text { no } \\
\text { difference }\end{array}$ & 63 IBS-D & $\begin{array}{l}26 \text { female } \\
37 \text { male }\end{array}$ & \\
\hline $\begin{array}{l}\text { Schmulson } \\
2012 \text { [117] }\end{array}$ & $62: 116$ & Rome II & serum & $\begin{array}{l}\text { IL-10 decreased. } \\
\text { TNF- } \alpha \text { increased }\end{array}$ & $\begin{array}{l}16 \text { IBS-C } \\
15 \text { IBS-D } \\
31 \text { IBS-M }\end{array}$ & $\begin{array}{l}34 \text { female } \\
28 \text { male }\end{array}$ & \\
\hline Gao 2013 [118] & $28: 15$ & Rome III & blood & $\begin{array}{l}\text { IL- } 1 \beta \text { increased. } \\
\text { IL-10 decreased }\end{array}$ & 28 IBS-D & $\begin{array}{l}16 \text { female } \\
12 \text { male }\end{array}$ & \\
\hline $\begin{array}{l}\text { Jizhong } \\
2016 \text { [115] }\end{array}$ & $102: 60$ & Rome III & $\begin{array}{l}\text { Peripheral } \\
\text { blood }\end{array}$ & $\begin{array}{l}\text { IL-6 mRNA } \\
\text { expression } \\
\text { increased. IL-10 } \\
\text { mRNA expression } \\
\text { decreased }\end{array}$ & $\begin{array}{l}30 \mathrm{IBS}-\mathrm{C} \\
44 \mathrm{IBS}-\mathrm{D} \\
28 \mathrm{IBS}-\mathrm{M} / \mathrm{A}\end{array}$ & $\begin{array}{l}39 \text { female } \\
63 \text { male }\end{array}$ & \\
\hline $\begin{array}{l}\text { Seyedmirzaee } \\
2016[116]\end{array}$ & $74: 75$ & Rome III & Serum & $\begin{array}{l}\text { IL-6, IL- } 8 \text { and } \\
\text { TNF- } \alpha \text { increased }\end{array}$ & $\begin{array}{l}29 \text { IBS-C } \\
34 \text { IBS-D } \\
11 \text { IBS-M }\end{array}$ & $\begin{array}{l}46 \text { female } \\
28 \text { male }\end{array}$ & \\
\hline Bennet 2016 [40] & $144: 42$ & Rome III & Serum & $\begin{array}{l}\text { IL-5, IL-6, IL-8, } \\
\text { IL-10, IL-12p70, } \\
\text { IL-13, IL-17A, } \\
\text { TNF and IFN- } \gamma \text { no } \\
\text { differences. IL-6 } \\
\text { and IL-8 tended to } \\
\text { be increased and } \\
\text { IFN- } \gamma \text { tended to be } \\
\text { decreased }\end{array}$ & $\begin{array}{l}35 \text { IBS-C } \\
58 \text { IBS-D } \\
51 \text { IBS-nonC-nonD }\end{array}$ & $\begin{array}{l}69 \% \text { female } \\
31 \% \text { male }\end{array}$ & \\
\hline $\begin{array}{l}\text { Choghakhori } \\
2017 \text { [39] }\end{array}$ & $90: 90$ & Rome III & Serum & $\begin{array}{l}\text { TNF- } \alpha \text { and IL-17 } \\
\text { increased. IL-10 } \\
\text { decreased }\end{array}$ & $\begin{array}{l}30 \text { IBS-C } \\
24 \text { IBS-D } \\
36 \text { IBS-A }\end{array}$ & $\begin{array}{l}61 \text { female } \\
29 \text { male }\end{array}$ & \\
\hline
\end{tabular}

CCL, chemokine C-C motif ligand; IBS, irritable bowel syndrome; IBS-C, constipation predominant; IBS-D, diarrhea predominant; IBS-M, mixed; IBS-A, with alternating stool pattern; IL, interleukin; IFN, interferon; PI-IBS, post-infectious; TNF, tumor necrosis factor

and TNF- $\alpha$ compared with the control group [110]. In a recent meta-analysis, sex-related analysis of cytokine imbalance in IBS demonstrated significantly lower levels of IL-10 in systemic circulation in male patients and significantly higher levels of TNF- $\alpha$ in female patients [119].

In addition, in some studies, cytokines such as chemokine (C-C motif) ligand-16 (CCL-16), macrophage migration inhibitory factor and monocyte chemotactin protein-1 were found to be elevated in the serum of IBS patients compared with controls, although the difference did not always reach statistical significance $[88,120]$. The gene expression level of CCL-16 in plasma was also shown to be greater, especially in
IBS-C patients, compared with healthy controls or those in the IBS-D subgroup [120].

Cytokine imbalance in mucosal biopsies may present more reliable insight into low-grade inflammation in IBS patients (Table 4). In two studies, tissue levels of cytokines such as IL4 , IL-6, IFN- $\gamma$ and TNF- $\alpha$ measured from intestinal mucosal biopsies presented no differences between 38 IBS Rome III patients and 48 controls $[121,122]$. However, IFN- $\gamma$ levels were higher in the PI-IBS subgroup, but without statistical significance [122]. IL-10 levels appeared to be depressed [118,122] and IL$1 \beta$ levels elevated in the IBS-D and IBS-M subgroups [121] and in the total IBS population [118]. Additionally, soluble 
IL-2 receptor showed higher levels in IBS-D patients [60] and IL-8 was elevated in the IBS-D and IBS-M subgroups [121]. In ex vivo cultures of biopsy tissue from 28 non-PI-IBS Rome II patients, IL-1 $\beta$, IL- 6 and TNF- $\alpha$ secretion showed no differences compared to controls, while secretion of IL-8 was lower [123]. Cytokine expression measured by mRNA levels in mucosal biopsies exhibited no significant difference in IL-1 [63], IL$1 \beta$ [65,107], IL-2 [122], IL-4 [122], IL-6 [63,65], IL-8 [40,65], IL-12 [65], IL-13 [63] or TNF- $\alpha[40,65,107]$. In other studies, IL-1 $\beta[25,57]$, IL-8 [61], and IFN- $\gamma$ [122] mRNA expression was elevated; however, in all three studies the majority of the patient population was identified as PI-IBS or IBS-D. Furthermore Chen et al showed no differences in IFN- $\gamma$ mRNA levels between a non-PI-IBS population and controls in mucosal biopsies of colon and rectum [122]. Expression of IL-10 mRNA was reported to be significantly depressed in three studies with a total of 126 IBS patients $[61,65,122]$, although in one of these the difference was seen only in the female population [65]. These results were contradictory, as other studies at the same time reported no differences in IL-10 mRNA levels [63,107]. A recent study with sigmoidal colon biopsies from 109 Rome III patients found that IL-10 mRNA levels were lower, but without reaching statistical significance [40]. Finally, ex vivo stimulation of cultures of anaerobic bacteria derived from the colonic mucosa of 11 PI-IBS patients provided some interesting results. At baseline, only IL-13 release was significantly lower

Table 4 Cytokine expression in biopsies from the intestinal mucosa in IBS patients

\begin{tabular}{|c|c|c|c|c|c|c|c|}
\hline Author & $\begin{array}{c}\text { Number of } \\
\text { participants } \\
\text { (IBS: } \\
\text { controls) }\end{array}$ & $\begin{array}{l}\text { Diagnostic } \\
\text { criteria }\end{array}$ & Site & Results & Subtype & $\begin{array}{l}\text { Patients' } \\
\text { sex }\end{array}$ & Notes \\
\hline Gwee 2003 [25] & $8: 18$ & Rome I & $\begin{array}{l}\text { Rectal } \\
\text { biopsies }\end{array}$ & $\begin{array}{l}\text { IL-1 } \beta \text { mRNA } \\
\text { expression } \\
\text { increased }\end{array}$ & PI-IBS & $\begin{array}{l}4 \text { female } \\
4 \text { male }\end{array}$ & \\
\hline Wang 2004 [57] & $30: 12$ & Rome II & $\begin{array}{l}\text { Terminal } \\
\text { ileum and } \\
\text { rectosigmoid }\end{array}$ & $\begin{array}{l}\text { IL-1 } \beta \text { mRNA } \\
\text { expression } \\
\text { increased in } \\
\text { terminal ileum } \\
\text { and rectosigmoid } \\
\text { mucosa in PI-IBS } \\
\text { patients }\end{array}$ & $\begin{array}{l}15 \text { PI-IBS } \\
15 \text { non PI-IBS }\end{array}$ & & \\
\hline Macsharry 2008 [123] & $28: 10$ & Rome II & $\begin{array}{l}\text { Sigmoid } \\
\text { colon and } \\
\text { rectum }\end{array}$ & $\begin{array}{l}\text { In ex vivo cultures. } \\
\text { IL-1 } 1 \beta \text {, IL- } 6 \text { and } \\
\text { TNF } \alpha \text { secretion } \\
\text { no differences. } \\
\text { Reduced secretion } \\
\text { of IL-8 }\end{array}$ & $\begin{array}{l}19 \% \text { IBS-C } \\
29 \% \text { IBS-D } \\
52 \% \text { IBS-M }\end{array}$ & 29 female & $\begin{array}{l}\text { No } \\
\text { PI-IBS }\end{array}$ \\
\hline Goral 2010 [60] & $72: 50$ & Rome III & $\begin{array}{l}\text { Cecum and } \\
\text { rectum }\end{array}$ & $\begin{array}{l}\text { sIL-2 receptor } \\
\text { levels increased in } \\
\text { IBS-D }\end{array}$ & $\begin{array}{l}32 \text { IBS-C } \\
40 \text { IBS-D }\end{array}$ & & \\
\hline Foley 2011 [63] & $20: 29$ & Rome III & Duodenal & $\begin{array}{l}\text { IL-1, IL-6, IL-10 } \\
\text { and IL-13 mRNA } \\
\text { numerically } \\
\text { higher but } \\
\text { without statistical } \\
\text { significance }\end{array}$ & 20 IBS-D & $\begin{array}{l}13 \text { female } \\
7 \text { male }\end{array}$ & \\
\hline De Silva 2012 [61] & $49: 14$ & Rome III & $\begin{array}{l}\text { Ileum, } \\
\text { cecum, } \\
\text { ascending, } \\
\text { transverse, } \\
\text { descending } \\
\text { colon and } \\
\text { rectum }\end{array}$ & $\begin{array}{l}\text { Expression of } \\
\text { IL-8 mRNA was } \\
\text { increased and } \\
\text { expression of IL-10 } \\
\text { mRNA decreased }\end{array}$ & 49 IBS-D & $\begin{array}{l}13 \text { female } \\
36 \text { male }\end{array}$ & \\
\hline Belmonte 2012 [121] & $48: 31$ & Rome III & $\begin{array}{l}\text { Descending } \\
\text { colon }\end{array}$ & $\begin{array}{l}\text { IL- } 8 \text { and } \\
\text { IL- } 1 \beta \text { mucosal } \\
\text { concentration was } \\
\text { increased in IBS-D } \\
\text { and IBS-M. No } \\
\text { changes in IFN- } \gamma \\
\text { TNF- } \alpha \text { and IL- } 6\end{array}$ & $\begin{array}{l}14 \text { IBS-C } \\
20 \text { IBS-D } \\
14 \text { IBS-M }\end{array}$ & $\begin{array}{l}37 \text { female } \\
11 \text { male }\end{array}$ & \\
\hline
\end{tabular}


10 N. Lazaridis and G. Germanidis

Table 4 (Continued)

\begin{tabular}{|c|c|c|c|c|c|c|c|}
\hline Author & $\begin{array}{c}\text { Number of } \\
\text { participants } \\
\text { (IBS: } \\
\text { controls) }\end{array}$ & $\begin{array}{l}\text { Diagnostic } \\
\text { criteria }\end{array}$ & Site & Results & Subtype & $\begin{array}{l}\text { Patients' } \\
\text { sex }\end{array}$ & Notes \\
\hline Chang 2012 [65] & $39: 34$ & Rome II & $\begin{array}{l}\text { Sigmoid } \\
\text { colon }\end{array}$ & $\begin{array}{l}\text { mRNA levels of } \\
\text { IL-1 } \beta \text {, IL-6, IL- } 8 \text {, } \\
\text { IL-12 and TNF- } \alpha \\
\text { no differences. } \\
\text { Female patients } \\
\text { had lower IL-10 } \\
\text { than female } \\
\text { controls }\end{array}$ & $\begin{array}{l}35.5 \% \text { IBS-C } \\
33.3 \% \text { IBS-D } \\
31.1 \% \text { IBS-M }\end{array}$ & $\begin{array}{l}22 \text { female } \\
17 \text { male }\end{array}$ & \\
\hline Chen 2012 [122] & $38: 20$ & Rome III & $\begin{array}{l}\text { Ascending, } \\
\text { descending } \\
\text { colon and } \\
\text { rectum }\end{array}$ & $\begin{array}{l}\text { IFN- } \gamma \text { mRNA } \\
\text { levels increased } \\
\text { in PI-IBS. IL-10 } \\
\text { mRNA levels } \\
\text { decreased in } \\
\text { PI-IBS. IL-12 and } \\
\text { IL-4 mRNA no } \\
\text { differences. In } \\
\text { non PI-IBS no } \\
\text { differences with } \\
\text { controls. } \\
\text { IFN- } \gamma \text { protein } \\
\text { expression was up } \\
\text { regulated in PI-IBS } \\
\text { but not statistically } \\
\text { important. IL-12, } \\
\text { IL-4 protein } \\
\text { expression no } \\
\text { difference. } \\
\text { IL-10 expression } \\
\text { was significantly } \\
\text { lower in PI-IBS }\end{array}$ & $\begin{array}{l}20 \text { PI-IBS } \\
18 \text { non PI-IBS }\end{array}$ & $\begin{array}{l}17 \text { female } \\
21 \text { male }\end{array}$ & \\
\hline Gao 2013 [118] & 28:15 & Rome III & $\begin{array}{l}\text { Sigmoid } \\
\text { colon }\end{array}$ & $\begin{array}{l}\text { IL-1 } \beta \text { levels were } \\
\text { increased. IL-10 } \\
\text { was reduced }\end{array}$ & 28 IBS-D & $\begin{array}{l}16 \text { female } \\
12 \text { male }\end{array}$ & \\
\hline Swan 2013 [107] & $55: 26$ & Rome II & Rectum & $\begin{array}{l}\text { IL-10, IL- } 1 \beta \text { and } \\
\text { TNF- } \alpha \text { mRNA } \\
\text { expression had no } \\
\text { differences }\end{array}$ & $\begin{array}{l}18 \text { IBS-C } \\
37 \text { IBS-D }\end{array}$ & $\begin{array}{l}41 \text { female } \\
14 \text { male }\end{array}$ & \\
\hline Sundin 2015 [124] & $11: 10$ & Rome III & $\begin{array}{l}\text { Sigmoid } \\
\text { colon }\end{array}$ & $\begin{array}{l}\text { Ex vivo cultures. } \\
\text { At baseline } \\
\text { IL-13 release } \\
\text { was significantly } \\
\text { decreased. IL-1 } \beta \text {, } \\
\text { IL-2, IL-8, IL-10, } \\
\text { IL-17, TNF- } \alpha \text { and } \\
\text { IFN- } \gamma \text { did not differ } \\
\text { significantly. } \\
\text { Mixed results } \\
\text { after bacteria } \\
\text { stimulation. IL-1 } \beta \\
\text { was increased } \\
\text { after bacteria } \\
\text { stimulation with } \\
\text { Subdoligranulum } \\
\text { variabil }\end{array}$ & $\begin{array}{l}10 \text { IBS-D } \\
1 \text { IBS-M }\end{array}$ & $\begin{array}{l}7 \text { female } \\
4 \text { male }\end{array}$ & \\
\hline
\end{tabular}


Table 4 (Continued)

\begin{tabular}{|c|c|c|c|c|c|c|c|}
\hline Author & $\begin{array}{l}\text { Number of } \\
\text { participants } \\
\text { (IBS: } \\
\text { controls) }\end{array}$ & $\begin{array}{l}\text { Diagnostic } \\
\text { criteria }\end{array}$ & Site & Results & Subtype & $\begin{array}{l}\text { Patients' } \\
\text { sex }\end{array}$ & Notes \\
\hline Bennet 2016 [40] & $109: 36$ & Rome III & $\begin{array}{l}\text { Sigmoid } \\
\text { colon }\end{array}$ & $\begin{array}{l}\text { Mucosal mRNA } \\
\text { levels of IL-8, IL-10 } \\
\text { and TNF had no } \\
\text { differences. IL-10 } \\
\text { mRNA tended to } \\
\text { be decreased }\end{array}$ & $\begin{array}{l}31 \text { IBS-C } \\
42 \text { IBS-D } \\
36 \text { IBS-nonCnonD }\end{array}$ & $\begin{array}{l}69 \% \\
\text { female } \\
31 \% \text { male }\end{array}$ & \\
\hline
\end{tabular}

IBS, irritable bowel syndrome; IBS-C, constipation-predominant; IBS-D, diarrhea-predominant; IBS-M, mixed; IL, interleukin; IFN, interferon; PI-IBS, post-infectious; TNF, tumor necrosis factor

compared to healthy controls, while IL-1 $\beta$, IL-2, IL-8, IL-10, IL17, TNF- $\alpha$, and IFN- $\gamma$ did not differ significantly. The results after stimulation were diverse and levels of cytokine release mainly remained unaltered. However, IL- $1 \beta$ was increased after bacterial stimulation with Subdoligranulum variabile in IBS patients [124].

The genetic predisposition of IBS patients to produce increased or decreased levels of cytokines has been subjected to some investigation. Polymorphisms in the cytokine-encoding genes and alterations in allele and genotype frequencies have been reported in IBS patients and may result in higher or lower production of some cytokines [125-127]. Moreover, SNPs in the IL-6 region were associated with an increased risk of developing PI-IBS [128]. Assessment of the IL-10 genotype was performed in blood samples from 230 Rome I IBS patients and 450 healthy controls. Interestingly, fewer IBS patients had the high-producer genotype for IL-10 compared with controls. Conversely, genotype frequencies for transforming growth factor- $\beta$ were not altered in a smaller group of participants [129]. In addition, in 111 Rome II IBS patients, the heterozygous TNF- $\alpha$ genotype was significantly more common compared with 162 healthy controls. No differences were found in IL-10 genotypes and allele frequencies between patients and controls [130]. Altered gene expression of cytokines IL-10, IL-1 $\beta$, and transforming growth factor $\beta$ were also observed in colonic tissue [123]. IL10 polymorphisms were analyzed in blood samples from 94 children and 102 controls, and genotype, allele or haplotype frequencies remained similar between the two groups [105].

\section{Toll-like receptors (TLRs) and inflammasomes}

TLRs are a family of transmembrane innate immune receptors that recognize various bacterial and viral cell components, known as pathogen-associated molecular patterns, and regulate the immune response [131,132]. In animal models, TLRs appear upregulated in response to stress and this upregulation seems to contribute to visceral hypersensitivity $[133,134]$. Furthermore, evaluation of potential genetic involvement in PI-IBS pathogenesis, studied after an outbreak of acute gastroenteritis, found two gene variants located in the TLR9 region. Moreover those SNPs were identified as independent risk factors for developing PIIBS [128]. Hence, research focusing on the role of TLRs and alterations in TLR signaling in dysregulated innate immune response could inform investigations into the pathogenesis of IBS (Table 5).

Expression of TLRs on blood monocytes of 74 Rome II IBS patients demonstrated higher levels of TLR2 expression compared to controls, while no differences were evident in TLR4 expression. No correlation between TLR expression and IBS subtypes according to bowel habits could be established [108]. Another study measured cytokine production after TLR agonist-induced stimulation in whole blood cultures. Interestingly, agonists for TLR2-5 and TLR7-8 enhanced cytokine levels in 30 Rome II IBS patients compared with controls. The TLR4 agonist LPS and the TLR5 agonist flagellin increased IL- $1 \beta$ and TNF- $\alpha$ release. In addition the TLR8 agonist ssRNA40 (single-stranded RNA oligonucleotide) stimulated the expression of all relevant cytokines (IL-1 $\beta$, IL-6, IL- 8 , and TNF- $\alpha$ ) in whole blood supernatants. No differences were found in cytokine production after stimulation with TLR1, TLR6, and TLR9 agonists [111].

In a recent large study with 102 IBS patients, both TLR2 and TLR4 mRNA levels were elevated in peripheral blood samples compared to controls. Furthermore, when depression scores were used to divide different categories of IBS patients, the subgroup defined as IBS with depression had significantly higher levels of TLR mRNA compared to the non-depressed subgroup [115]. The kynurenine:tryptophan ratio has been evaluated in whole blood cultures stimulated with TLR agonists. Researchers demonstrated a different tryptophan degradation profile induced by some TLR agonists and this may implicate a possible TLR dysfunction in low-grade inflammation, caused by either increased expression or enhanced sensitivity [135].

Increases in TLR levels in systemic circulation strengthen the hypothesis for the potential role of innate immune dysfunction in IBS pathophysiology, although increased serum levels of LPS and antiflagellin antibodies have also been found [136]. Nevertheless, similar results would need to be documented in the intestinal mucosa. A study with 26 Rome II IBS female patients investigated TLR1-10 expression using quantitative real-time polymerase chain reaction in biopsies from sigmoid colon and rectum. Expression of TLR4 and TLR5 was elevated, while both TLR7 and TLR8 expression were significantly lower compared to controls. Interestingly, expression of TLR4 was fourfold higher compared with controls, while this increase was lower than that observed in IBD patients (even 
12 N. Lazaridis and G. Germanidis

Table 5 TLR expression in blood and biopsies from the intestinal mucosa of IBS patients

\begin{tabular}{|c|c|c|c|c|c|c|c|}
\hline Author & $\begin{array}{c}\text { Number of } \\
\text { participants } \\
\text { (IBS: } \\
\text { controls) }\end{array}$ & $\begin{array}{l}\text { Diagnostic } \\
\text { criteria }\end{array}$ & Site & Results & Subtype & $\begin{array}{l}\text { Patients' } \\
\text { sex }\end{array}$ & extra \\
\hline $\begin{array}{l}\text { McKernan } \\
2011 \text { [111] }\end{array}$ & $30: 30$ & Rome II & $\begin{array}{l}\text { Whole } \\
\text { blood } \\
\text { cultures }\end{array}$ & $\begin{array}{l}\text { TLR1, TLR6 and } \\
\text { TRL9 agonist induce } \\
\text { no difference in } \\
\text { cytokine levels. TLR2 } \\
\text { agonist increases } \\
\text { TNF- } \alpha \text {. TLR3 } \\
\text { \& TLR7 agonist } \\
\text { increases IL-8. TLR4 } \\
\text { \& TLR5 increases } \\
\text { IL-1 } \beta \text { and TNF- } \alpha \text {. } \\
\text { TLR8 agonist } \\
\text { increases IL6, IL-8, } \\
\text { IL-1 } \beta \text { and TNF- } \alpha\end{array}$ & $\begin{array}{l}10 \text { IBS-C } \\
9 \text { IBS-D } \\
11 \text { IBS-A }\end{array}$ & $\begin{array}{l}25 \text { female } \\
5 \text { male }\end{array}$ & Non PI-IBS \\
\hline Clarke 2012 [135] & $25: 37$ & Rome II & $\begin{array}{l}\text { Whole } \\
\text { blood } \\
\text { cultures }\end{array}$ & $\begin{array}{l}\text { Plasma tryptophan } \\
\text { levels no difference. } \\
\text { Plasma kynurenine } \\
\text { levels elevated. } \\
\text { TLRs induced } \\
\text { alteration in } \\
\text { tryptophan } \\
\text { degradation }\end{array}$ & $\begin{array}{l}9 \text { IBS-C } \\
8 \text { IBS-D } \\
8 \text { IBS-A }\end{array}$ & $\begin{array}{l}20 \text { female } \\
5 \text { male }\end{array}$ & Non PI-IBS \\
\hline $\begin{array}{l}\text { Ohman } \\
2012 \text { [108] }\end{array}$ & $74: 30$ & Rome II & $\begin{array}{l}\text { Blood } \\
\text { monocytes }\end{array}$ & $\begin{array}{l}\text { Increased } \\
\text { expression of TLR2. } \\
\text { No difference in } \\
\text { TLR4 }\end{array}$ & $\begin{array}{l}11 \text { IBS-C } \\
26 \text { IBS-D } \\
31 \text { IBS-M }\end{array}$ & $\begin{array}{l}52 \text { female } \\
22 \text { male }\end{array}$ & \\
\hline Jizhong 2016 [115] & $102: 60$ & Rome III & $\begin{array}{l}\text { Peripheral } \\
\text { blood }\end{array}$ & $\begin{array}{l}\text { IL-6 mRNA } \\
\text { expression } \\
\text { increased. IL-10 } \\
\text { mRNA expression } \\
\text { decreased }\end{array}$ & $\begin{array}{l}30 \text { IBS-C } \\
44 \text { IBS-D } \\
28 \text { IBS-M/A }\end{array}$ & $\begin{array}{l}39 \text { female } \\
63 \text { male }\end{array}$ & $\begin{array}{l}\text { Depressed } \\
\text { IBS patients } \\
\text { enhanced } \\
\text { results } \\
\text { than non } \\
\text { depressed. }\end{array}$ \\
\hline Brint 2011 [137] & $26: 19$ & Rome II & $\begin{array}{l}\text { Sigmoid } \\
\text { colon and } \\
\text { rectum }\end{array}$ & $\begin{array}{l}\text { RT-PCR analysis. } \\
\text { Increased } \\
\text { expression of TLR4 } \\
\text { \& TLR5. Decreased } \\
\text { of TLR7 \& TLR8 }\end{array}$ & $\begin{array}{l}19 \% \text { IBS-C } \\
29 \% \text { IBS-D } \\
52 \% \text { IBS-A/M }\end{array}$ & 26 female & \\
\hline Brint 2011 [137] & $9: 8$ & Rome II & $\begin{array}{l}\text { Sigmoid } \\
\text { colon and } \\
\text { rectum }\end{array}$ & $\begin{array}{l}\text { Microarray analysis. } \\
\text { Increase in TLR4 } \\
\text { expression. } \\
\text { In microarray gene } \\
\text { expression of TLR } \\
\text { genes }\end{array}$ & $\begin{array}{l}2 \text { IBS-C } \\
2 \text { IBS-D } \\
5 \text { IBS-A }\end{array}$ & 9 female & $\begin{array}{l}\text { Population } \\
\text { from } \\
\text { previous } \\
\text { study of } \\
\text { MacSharry } \\
2008 \text { [123] }\end{array}$ \\
\hline $\begin{array}{l}\text { Belmonte } \\
2012 \text { [121] }\end{array}$ & $48: 31$ & Rome III & $\begin{array}{l}\text { Descending } \\
\text { colon }\end{array}$ & $\begin{array}{l}\text { No difference in TLR2 } \\
\text { and TLR4 mRNA } \\
\text { expression. Increased } \\
\text { TLR2 and TLR4 } \\
\text { mRNA expression in } \\
\text { IBS-M subgroup }\end{array}$ & $\begin{array}{l}14 \text { IBS-C } \\
20 \text { IBS-D } \\
14 \text { IBS-M }\end{array}$ & $\begin{array}{l}37 \text { female } \\
11 \text { male }\end{array}$ & \\
\hline Kocak 2016 [138] & $51: 15$ & Rome II & $\begin{array}{l}\text { Sigmoid } \\
\text { colon and } \\
\text { rectum }\end{array}$ & $\begin{array}{l}\text { Increased colonic } \\
\text { tissue levels of TLR4. } \\
\text { Increased colonic } \\
\text { tissue levels of TLR2 } \\
\text { only for IBS-D }\end{array}$ & $\begin{array}{l}31 \text { IBS-C } \\
20 \text { IBS-D }\end{array}$ & $\begin{array}{l}43 \text { female } \\
8 \text { male }\end{array}$ & \\
\hline
\end{tabular}

IBS, irritable bowel syndrome; IBS-A, with alternating stool pattern; IBS-C, constipation predominant; IBS-D, diarrhea predominant; IBS-M, mixed; IL, interleukin; PI-IBS, post-infectious; TLR, toll-like receptor; TNF, tumor necrosis factor 
from those with active disease). In the same study, other TLR regulatory proteins (Tollip, IL-1 receptor-associated kinase) were measured; however, they showed no major differences when compared with controls, with the exception of single immunoglobulin IL-1 receptor-related molecule, which was upregulated [137].

Another study with 48 Rome III IBS patients evaluated the mRNA expression of TLR2 and TLR4 in mucosal biopsies from the descending colon and showed no significant difference compared with controls. When mRNA expression was analyzed in the IBS subgroups, both TLR2 and TLR4 levels were significantly elevated in IBS-M patients. In addition, TLR2 and TLR4 expression had a positive correlation with the duration of symptoms in IBS patients and in the IBS-M group [121]. Finally, in a very recent study where colonic tissue samples from 51 Rome II IBS patients were analyzed, higher TLR4 levels were found. TLR2 levels were also elevated, though without statistical significance in the total IBS population. In the IBS-D subgroup of patients, the colonic tissue levels of TLR2 were significantly higher than those of controls [138].

The innate immune system is activated through a vast variety of receptors, which recognize potential threats and trigger immune responses. Another complex of pattern recognition receptors is called inflammasomes; these are a cytoplasmic multi-protein family that activate caspase- 1 and induce secretion of IL-1 $\beta$ and IL-18, resulting in cell death by pyroptosis. Nucleotide-binding domain and leucine-rich repeat-containing proteins assemble canonical inflammasomes (NLRPs) that promote caspase-1 activation [139,140]. A role for NLR inflammasome modulation and caspase-1 activation in mucosal inflammation has been implicated in IBD and IBS pathophysiology [141]. Recently, a small study with 7 IBD and 6 IBS-D Rome III patients, compared with 13 healthy controls, reported elevated intestinal epithelial cell counts with activated caspase-1 staining [142]. In animal studies, stress-induced small bowel inflammation was associated with NLRP-6 downregulation and alterations in gut microbiota. Interestingly, probiotic therapy ameliorated the induced enteritis, reinforcing the correlation between mild inflammation, gut dysbiosis and appearance of IBS or IBS-like symptoms [143]. Furthermore, both NLRP-3 and caspase-1 were significantly more expressed in the terminal ileal tissues of mice with PI-IBS from Trichinella spiralis compared with normal control mice. Elevated expression of IL- $1 \beta$ and IL-18 was also documented in PI-IBS mice [144]. Additional studies are required in order to elucidate the possible role of inflammasomes in IBS pathogenesis.

\section{Concluding remarks}

A large number of studies have explored the role of innate immune response dysfunction in the pathophysiology of IBS and the potential implication of low-grade inflammation in both systemic circulation and intestinal mucosa. There is some evidence to support a predominantly inflammatory process occurring locally, in the intestinal mucosa, and perhaps systemically. However, many of the studies, which have focused on certain cell types, cytokines or pathogen recognition receptors, have yielded conflicting results. Hence, the underlining mechanisms are still unclear and the specific role of immune cells and mediators is elusive. To better understand the complex IBS pathogenesis, specific immune response pathways should be investigated and understood in depth in well-designed experimental or translational studies. Interactions between gut microbiota, immune activation and dysfunction of the enteric nervous system need to be more clearly delineated, to reach a convincing hypothesis regarding the pathophysiologic mechanism of IBS. Further comprehension of these factors could broaden therapeutic possibilities and ameliorate the burden of the disease.

\section{References}

1. Lacy BE, Mearin F, Chang L, et al. Bowel disorders. Gastroenterology 2016;150:1393-1407.e5.

2. Drossman DA, Camilleri M, Mayer EA, Whitehead WE. AGA technical review on irritable bowel syndrome. Gastroenterology 2002;123:2108-2131.

3. Lovell RM, Ford AC. Global prevalence of and risk factors for irritable bowel syndrome: a meta-analysis. Clin Gastroenterol Hepatol 2012;10:712-721.

4. Sperber AD, Dumitrascu D, Fukudo S, et al. The global prevalence of IBS in adults remains elusive due to the heterogeneity of studies: a Rome Foundation working team literature review. Gut 2017;66:1075-1082.

5. Olafsdottir LB, Gudjonsson H, Jonsdottir HH, Thjodleifsson B. Stability of the irritable bowel syndrome and subgroups as measured by three diagnostic criteria - a 10-year follow-up study. Aliment Pharmacol Ther 2010;32:670-680.

6. Hillilä MT, Färkkilä MA. Prevalence of irritable bowel syndrome according to different diagnostic criteria in a non-selected adult population. Aliment Pharmacol Ther 2004;20:339-345.

7. Pimentel M, Talley NJ, Quigley EM, Hani A, Sharara A, Mahachai V. Report from the multinational irritable bowel syndrome initiative 2012. Gastroenterology 2013;144:e1-e5.

8. Everhart JE, Ruhl CE. Burden of digestive diseases in the United States part II: lower gastrointestinal diseases. Gastroenterology 2009;136:741-754.

9. Hulisz D. The burden of illness of irritable bowel syndrome: current challenges and hope for the future. J Manag Care Pharm 2004;10:299-309.

10. Mikocka-Walus A, Turnbull D, Moulding N, Wilson I, Andrews JM, Holtmann G. Psychological comorbidity and complexity of gastrointestinal symptoms in clinically diagnosed irritable bowel syndrome patients. J Gastroenterol Hepatol 2008;23:1137-1143.

11. Holtmann GJ, Ford AC, Talley NJ. Pathophysiology of irritable bowel syndrome. Lancet Gastroenterol Hepatol 2016;1:133-146.

12. Ford AC, Talley NJ. Mucosal inflammation as a potential etiological factor in irritable bowel syndrome: a systematic review. J Gastroenterol 2011;46:421-431.

13. Spiller R, Garsed K. Postinfectious irritable bowel syndrome. Gastroenterology 2009;136:1979-1988.

14. Piche T, Barbara G, Aubert P, et al. Impaired intestinal barrier integrity in the colon of patients with irritable bowel syndrome: involvement of soluble mediators. Gut 2009;58:196-201.

15. Simrén M, Barbara G, Flint HJ, et al; Rome Foundation Committee. Intestinal microbiota in functional bowel disorders: a Rome 
foundation report. Gut 2013;62:159-176.

16. Qin HY, Cheng CW, Tang XD, Bian ZX. Impact of psychological stress on irritable bowel syndrome. World $J$ Gastroenterol 2014;20:14126-14131.

17. Beatty JK, Bhargava A, Buret AG. Post-infectious irritable bowel syndrome: mechanistic insights into chronic disturbances following enteric infection. World J Gastroenterol 2014;20:3976-3985.

18. Halvorson HA, Schlett CD, Riddle MS. Postinfectious irritable bowel syndrome-a meta-analysis. Am $J$ Gastroenterol 2006;101:1894-1899; quiz 1942.

19. Thabane M, Kottachchi DT, Marshall JK. Systematic review and meta-analysis: The incidence and prognosis of post-infectious irritable bowel syndrome. Aliment Pharmacol Ther 2007;26:535-544.

20. Downs IA, Aroniadis OC, Kelly L, Brandt LJ. Postinfection irritable bowel syndrome: the links between gastroenteritis, inflammation, the microbiome, and functional disease. J Clin Gastroenterol 2017;51:869-877.

21. Sundin J, Rangel I, Kumawat AK, Hultgren-Hörnquist E, Brummer RJ. Aberrant mucosal lymphocyte number and subsets in the colon of post-infectious irritable bowel syndrome patients. Scand J Gastroenterol 2014;49:1068-1075.

22. Spiller RC, Jenkins D, Thornley JP, et al. Increased rectal mucosal enteroendocrine cells, $\mathrm{T}$ lymphocytes, and increased gut permeability following acute Campylobacter enteritis and in postdysenteric irritable bowel syndrome. Gut 2000;47:804-811.

23. Lee KJ, Kim YB, Kim JH, Kwon HC, Kim DK, Cho SW. The alteration of enterochromaffin cell, mast cell, and lamina propria $\mathrm{T}$ lymphocyte numbers in irritable bowel syndrome and its relationship with psychological factors. J Gastroenterol Hepatol 2008;23:1689-1694.

24. Jalanka-Tuovinen J, Salojärvi J, Salonen A, et al. Faecal microbiota composition and host-microbe cross-talk following gastroenteritis and in postinfectious irritable bowel syndrome. Gut 2014;63:1737-1745.

25. Gwee KA, Collins SM, Read NW, et al. Increased rectal mucosal expression of interleukin 1beta in recently acquired post-infectious irritable bowel syndrome. Gut 2003;52:523-526.

26. Spiller R, Major G. IBS and IBD - separate entities or on a spectrum? Nat Rev Gastroenterol Hepatol 2016;13:613-621.

27. Scanu AM, Bull TJ, Cannas S, et al. Mycobacterium avium subspecies paratuberculosis infection in cases of irritable bowel syndrome and comparison with Crohn's disease and Johne's disease: common neural and immune pathogenicities. J Clin Microbiol 2007;45:3883-3890.

28. Simrén M, Axelsson J, Gillberg R, Abrahamsson H, Svedlund J, Björnsson ES. Quality of life in inflammatory bowel disease in remission: the impact of IBS-like symptoms and associated psychological factors. Am J Gastroenterol 2002;97:389-396.

29. O'Leary C, Wieneke P, Buckley S, et al. Celiac disease and irritable bowel-type symptoms. Am J Gastroenterol 2002;97:1463-1467.

30. Limsui D, Pardi DS, Camilleri M, et al. Symptomatic overlap between irritable bowel syndrome and microscopic colitis. Inflamm Bowel Dis 2007;13:175-181.

31. Porter CK, Cash BD, Pimentel M, Akinseye A, Riddle MS. Risk of inflammatory bowel disease following a diagnosis of irritable bowel syndrome. BMC Gastroenterol 2012;12:55.

32. Gazouli M, Wouters MM, Kapur-Pojskić L, et al. Lessons learnedresolving the enigma of genetic factors in IBS. Nat Rev Gastroenterol Hepatol 2016;13:77-87.

33. Zucchelli M, Camilleri M, Andreasson AN, et al. Association of TNFSF15 polymorphism with irritable bowel syndrome. Gut 2011;60:1671-1677.

34. Czogalla B, Schmitteckert S, Houghton LA, et al. A meta-analysis of immunogenetic case-control association studies in irritable bowel syndrome. Neurogastroenterol Motil 2015;27:717-727.

35. McCullough R, McCullough J. Deciphering the pathophysiology of irritable bowel syndrome and functional gastrointestinal disordersan alternative model for pathogenesis: cytokine controlled transepithelial multi-feedback loop. Transl Gastroenterol Hepatol 2017;2:18.

36. Martin-Viñas JJ, Quigley EM. Immune response in irritable bowel syndrome: A systematic review of systemic and mucosal inflammatory mediators. J Dig Dis 2016;17:572-581.

37. Barbara G. Editorial: toll-like receptor expression in irritable bowel syndrome: on the alert for a microbial threat? Am J Gastroenterol 2011;106:337-339.

38. Ohman L, Simrén M. Pathogenesis of IBS: role of inflammation, immunity and neuroimmune interactions. Nat Rev Gastroenterol Hepatol 2010;7:163-173.

39. Choghakhori R, Abbasnezhad A, Hasanvand A, Amani R. Inflammatory cytokines and oxidative stress biomarkers in irritable bowel syndrome: association with digestive symptoms and quality of life. Cytokine 2017;93:34-43.

40. Bennet SM, Polster A, Törnblom H, et al. Global cytokine profiles and association with clinical characteristics in patients with irritable bowel syndrome. Am J Gastroenterol 2016;111:1165-1176.

41. Chadwick VS, Chen W, Shu D, et al. Activation of the mucosal immune system in irritable bowel syndrome. Gastroenterology 2002;122:1778-1783.

42. Liebregts T, Adam B, Bredack C, et al. Immune activation in patients with irritable bowel syndrome. Gastroenterology 2007;132:913-920.

43. Ohman L, Isaksson S, Lindmark AC, et al. T-cell activation in patients with irritable bowel syndrome. Am J Gastroenterol 2009; 104:1205-1212.

44. Dunlop SP, Jenkins D, Neal KR, et al. Randomized, double-blind, placebo-controlled trial of prednisolone in post-infectious irritable bowel syndrome. Aliment Pharmacol Ther 2003;18:77-84.

45. Barbara G, Cremon C, Annese V, et al. Randomised controlled trial of mesalazine in IBS. Gut 2016;65:82-90.

46. Reber LL, Sibilano R, Mukai K, Galli SJ. Potential effector and immunoregulatory functions of mast cells in mucosal immunity. Mucosal Immunol 2015;8:444-463.

47. Metcalfe DD, Baram D, Mekori YA. Mast cells. Physiol Rev 1997;77:1033-1079.

48. Wouters MM, Vicario M, Santos J. The role of mast cells in functional GI disorders. Gut 2016;65:155-168.

49. Martínez C, Lobo B, Pigrau M, et al. Diarrhoea-predominant irritable bowel syndrome: an organic disorder with structural abnormalities in the jejunal epithelial barrier. Gut 2013;62:1160-1168.

50. El-Salhy M, Gundersen D, Hatlebakk JG, Hausken T. Low-grade inflammation in the rectum of patients with sporadic irritable bowel syndrome. Mol Med Rep 2013;7:1081-1085.

51. Cremon C, Gargano L, Morselli-Labate AM, et al. Mucosal immune activation in irritable bowel syndrome: gender-dependence and association with digestive symptoms. Am J Gastroenterol 2009; 104:392-400.

52. Braak B, Klooker TK, Wouters MM, et al. Mucosal immune cell numbers and visceral sensitivity in patients with irritable bowel syndrome: is there any relationship? Am J Gastroenterol 2012;107:715-726.

53. Balestra B, Vicini R, Cremon C, et al. Colonic mucosal mediators from patients with irritable bowel syndrome excite enteric cholinergic motor neurons. Neurogastroenterol Motil 2012;24:1118e570.

54. Buhner S, Li Q, Vignali S, et al. Activation of human enteric neurons by supernatants of colonic biopsy specimens from patients with irritable bowel syndrome. Gastroenterology 2009;137:1425-1434.

55. Barbara G, Stanghellini V, De Giorgio R, et al. Activated mast cells in proximity to colonic nerves correlate with abdominal pain in irritable bowel syndrome. Gastroenterology 2004;126:693-702.

56. Wang SH, Dong L, Luo JY, et al. Decreased expression of serotonin 
in the jejunum and increased numbers of mast cells in the terminal ileum in patients with irritable bowel syndrome. World $J$ Gastroenterol 2007;13:6041-6047.

57. Wang LH, Fang XC, Pan GZ. Bacillary dysentery as a causative factor of irritable bowel syndrome and its pathogenesis. Gut 2004;53:1096-1101.

58. Park JH, Rhee PL, Kim HS, et al. Mucosal mast cell counts correlate with visceral hypersensitivity in patients with diarrhea predominant irritable bowel syndrome. J Gastroenterol Hepatol 2006;21:71-78.

59. Guilarte M, Santos J, de Torres I, et al. Diarrhoea-predominant IBS patients show mast cell activation and hyperplasia in the jejunum. Gut 2007;56:203-209.

60. Goral V, Kucukoner M, Buyukbayram H. Mast cells count and serum cytokine levels in patients with irritable bowel syndrome. Hepatogastroenterology 2010;57:751-754.

61. De Silva AP, Nandasiri SD, Hewavisenthi J, et al. Subclinical mucosal inflammation in diarrhea-predominant irritable bowel syndrome (IBS) in a tropical setting. Scand J Gastroenterol 2012;47:619-624.

62. Vicario M, González-Castro AM, Martínez C, et al. Increased humoral immunity in the jejunum of diarrhoea-predominant irritable bowel syndrome associated with clinical manifestations. Gut 2015;64:1379-1388.

63. Foley S, Garsed K, Singh G, et al. Impaired uptake of serotonin by platelets from patients with irritable bowel syndrome correlates with duodenal immune activation. Gastroenterology 2011;140:1434-1443.e1.

64. Martínez C, Vicario M, Ramos L, et al. The jejunum of diarrheapredominant irritable bowel syndrome shows molecular alterations in the tight junction signaling pathway that are associated with mucosal pathobiology and clinical manifestations. Am J Gastroenterol 2012;107:736-746.

65. Chang L, Adeyemo M, Karagiannides I, et al. Serum and colonic mucosal immune markers in irritable bowel syndrome. Am J Gastroenterol 2012;107:262-272.

66. Schemann M, Camilleri M. Functions and imaging of mast cell and neural axis of the gut. Gastroenterology 2013;144:698-704.

67. Willot S, Gauthier C, Patey N, Faure C. Nerve growth factor content is increased in the rectal mucosa of children with diarrheapredominant irritable bowel syndrome. Neurogastroenterol Motil 2012;24:734-739, e347.

68. Barbara G, Wang B, Stanghellini V, et al. Mast cell-dependent excitation of visceral-nociceptive sensory neurons in irritable bowel syndrome. Gastroenterology 2007;132:26-37.

69. Wouters MM, Balemans D, Van Wanrooy S, et al. Histamine receptor H1-mediated sensitization of TRPV1 mediates visceral hypersensitivity and symptoms in patients with irritable bowel syndrome. Gastroenterology 2016;150:875-887.e9.

70. Wilcz-Villega EM, McClean S, O’Sullivan MA. Mast cell tryptase reduces junctional adhesion molecule-A (JAM-A) expression in intestinal epithelial cells: implications for the mechanisms of barrier dysfunction in irritable bowel syndrome. Am J Gastroenterol 2013;108:1140-1151.

71. Vivinus-Nébot M, Dainese R, Anty R, et al. Combination of allergic factors can worsen diarrheic irritable bowel syndrome: role of barrier defects and mast cells. Am J Gastroenterol 2012;107:75-81.

72. Klooker TK, Braak B, Koopman KE, et al. The mast cell stabiliser ketotifen decreases visceral hypersensitivity and improves intestinal symptoms in patients with irritable bowel syndrome. Gut 2010;59:1213-1221.

73. Bian ZX, Li Z, Huang ZX, et al. Unbalanced expression of proteaseactivated receptors- 1 and -2 in the colon of diarrhea-predominant irritable bowel syndrome patients. J Gastroenterol 2009;44:666-674.

74. Rothenberg ME, Hogan SP. The eosinophil. Annu Rev Immunol 2006;24:147-174.

75. Powell N, Walker MM, Talley NJ. Gastrointestinal eosinophils in health, disease and functional disorders. Nat Rev Gastroenterol Hepatol 2010;7:146-156.

76. Park KS, Ahn SH, Hwang JS, et al. A survey about irritable bowel syndrome in South Korea: prevalence and observable organic abnormalities in IBS patients. Dig Dis Sci 2008;53:704-711.

77. Walker MM, Talley NJ, Prabhakar M, et al. Duodenal mastocytosis, eosinophilia and intraepithelial lymphocytosis as possible disease markers in the irritable bowel syndrome and functional dyspepsia. Aliment Pharmacol Ther 2009;29:765-773.

78. Walker MM, Talley NJ, Inganäs L, et al. Colonic spirochetosis is associated with colonic eosinophilia and irritable bowel syndrome in a general population in Sweden. Hum Pathol 2015;46:277-283.

79. Piche T, Saint-Paul MC, Dainese R, et al. Mast cells and cellularity of the colonic mucosa correlated with fatigue and depression in irritable bowel syndrome. Gut 2008;57:468-473.

80. O'Sullivan M, Clayton N, Breslin NP, et al. Increased mast cells in the irritable bowel syndrome. Neurogastroenterol Motil 2000;12:449-457.

81. Kristjánsson G, Venge P, Wanders A, Lööf L, Hällgren R. Clinical and subclinical intestinal inflammation assessed by the mucosal patch technique: studies of mucosal neutrophil and eosinophil activation in inflammatory bowel diseases and irritable bowel syndrome. Gut 2004;53:1806-1812.

82. Emmanuel A, Landis D, Peucker M, Hungin AP. Faecal biomarker patterns in patients with symptoms of irritable bowel syndrome. Frontline Gastroenterol 2016;7:275-282.

83. Lettesjö H, Hansson T, Peterson C, et al. Detection of inflammatory markers in stools from patients with irritable bowel syndrome and collagenous colitis. Scand J Gastroenterol 2006;41:54-59.

84. Goepp J, Fowler E, McBride T, Landis D. Frequency of abnormal fecal biomarkers in irritable bowel syndrome. Glob Adv Health Med 2014;3:9-15.

85. Uz E, Türkay C, Aytac S, Bavbek N. Risk factors for irritable bowel syndrome in Turkish population: role of food allergy. J Clin Gastroenterol 2007;41:380-383.

86. Carroccio A, Mansueto P, Iacono G, et al. Non-celiac wheat sensitivity diagnosed by double-blind placebo-controlled challenge: exploring a new clinical entity. Am J Gastroenterol 2012;107:1898-1906; quiz 1907.

87. Carroccio A, Mansueto P, D’Alcamo A, Iacono G. Non-celiac wheat sensitivity as an allergic condition: personal experience and narrative review. Am J Gastroenterol 2013;108:1845-1852; quiz 1853.

88. Tülübaş F, Oran M, Mete R, et al. Investigation of serum macrophage migration inhibitor factor and monocyte chemotactic protein-1 levels in irritable bowel syndrome. Turk J Med Sci 2014;44:967-971.

89. Motzer SA, Jarrett M, Heitkemper MM, Tsuji J. Natural killer cell function and psychological distress in women with and without irritable bowel syndrome. Biol Res Nurs 2002;4:31-42.

90. Elsenbruch S, Lucas A, Holtmann G, et al. Public speaking stressinduced neuroendocrine responses and circulating immune cell redistribution in irritable bowel syndrome. Am J Gastroenterol 2006;101:2300-2307.

91. Elsenbruch S, Holtmann G, Oezcan D, et al. Are there alterations of neuroendocrine and cellular immune responses to nutrients in women with irritable bowel syndrome? Am J Gastroenterol 2004;99:703-710.

92. Kindt S, Van Oudenhove L, Broekaert D, et al. Immune dysfunction in patients with functional gastrointestinal disorders. Neurogastroenterol Motil 2009;21:389-398.

93. Kane SV, Sandborn WJ, Rufo PA, et al. Fecal lactoferrin is a sensitive and specific marker in identifying intestinal inflammation. Am J Gastroenterol 2003;98:1309-1314.

94. Oikonomou KA, Kapsoritakis AN, Theodoridou C, et al. Neutrophil gelatinase-associated lipocalin (NGAL) in inflammatory bowel disease: association with pathophysiology of inflammation, 
established markers, and disease activity. $J$ Gastroenterol 2012;47:519-530.

95. Langhorst J, Junge A, Rueffer A, et al. Elevated human betadefensin-2 levels indicate an activation of the innate immune system in patients with irritable bowel syndrome. Am J Gastroenterol 2009;104:404-410.

96. Harder J, Bartels J, Christophers E, Schröder JM. A peptide antibiotic from human skin. Nature 1997;387:861.

97. Wehkamp J, Harder J, Weichenthal $M$, et al. Inducible and constitutive beta-defensins are differentially expressed in Crohn's disease and ulcerative colitis. Inflamm Bowel Dis 2003;9:215-223.

98. Merad M, Manz MG. Dendritic cell homeostasis. Blood 2009;113:3418-3427.

99. Li M, Zhang L, Lu B, et al. Role of dendritic cell-mediated abnormal immune response in visceral hypersensitivity. Int J Clin Exp Med 2015;8:13243-13250.

100.Long Y, Wang W, Wang H, Hao L, Qian W, Hou X. Characteristics of intestinal lamina propria dendritic cells in a mouse model of postinfectious irritable bowel syndrome. J Gastroenterol Hepatol 2012;27:935-944.

101.Koido S, Ohkusa T, Kan S, et al. Production of corticotropinreleasing factor and urocortin from human monocyte-derived dendritic cells is stimulated by commensal bacteria in intestine. World J Gastroenterol 2014;20:14420-14429.

102.Hojo M, Ohkusa T, Tomeoku H, et al. Corticotropin-releasing factor secretion from dendritic cells stimulated by commensal bacteria. World J Gastroenterol 2011;17:4017-4022.

103.Lied GA, Vogelsang P, Berstad A, Appel S. Dendritic cell populations in patients with self-reported food hypersensitivity. Int J Gen Med 2011;4:389-396.

104.O'Mahony L, McCarthy J, Kelly P, et al. Lactobacillus and bifidobacterium in irritable bowel syndrome: symptom responses and relationship to cytokine profiles. Gastroenterology 2005; 128:541-551.

105. Hua MC, Chao HC, Yao TC, Lai MW, Huang JL; PATCH Study Group. Investigation of interleukin-10 promoter polymorphisms and interleukin-10 levels in children with irritable bowel syndrome. Gut Liver 2013;7:430-436.

106.Zhen Y, Chu C, Zhou S, Qi M, Shu R. Imbalance of tumor necrosis factor- $\alpha$, interleukin- 8 and interleukin-10 production evokes barrier dysfunction, severe abdominal symptoms and psychological disorders in patients with irritable bowel syndromeassociated diarrhea. Mol Med Rep 2015;12:5239-5245.

107.Swan C, Duroudier NP, Campbell E, et al. Identifying and testing candidate genetic polymorphisms in the irritable bowel syndrome (IBS): association with TNFSF15 and TNFa. Gut 2013;62:985-994.

108. Ohman L, Lindmark AC, Isaksson S, et al. Increased TLR2 expression on blood monocytes in irritable bowel syndrome patients. Eur J Gastroenterol Hepatol 2012;24:398-405.

109. Hua MC, Lai MW, Kuo ML, Yao TC, Huang JL, Chen SM. Decreased interleukin-10 secretion by peripheral blood mononuclear cells in children with irritable bowel syndrome. J Pediatr Gastroenterol Nutr 2011;52:376-381.

110.Scully P, McKernan DP, Keohane J, et al. Plasma cytokine profiles in females with irritable bowel syndrome and extra-intestinal comorbidity. Am J Gastroenterol 2010;105:2235-2243.

111.McKernan DP, Gaszner G, Quigley EM, Cryan JF, Dinan TG. Altered peripheral toll-like receptor responses in the irritable bowel syndrome. Aliment Pharmacol Ther 2011;33:1045-1052.

112. Dinan TG, Quigley EM, Ahmed SM, et al. Hypothalamicpituitary-gut axis dysregulation in irritable bowel syndrome: plasma cytokines as a potential biomarker? Gastroenterology 2006;130:304-311.

113. Rana SV, Sharma S, Sinha SK, Parsad KK, Malik A, Singh K. Pro-inflammatory and anti-inflammatory cytokine response in diarrhoea-predominant irritable bowel syndrome patients. Trop
Gastroenterol 2012;33:251-256.

114. Dinan TG, Clarke G, Quigley EM, et al. Enhanced cholinergicmediated increase in the pro-inflammatory cytokine IL-6 in irritable bowel syndrome: role of muscarinic receptors. Am J Gastroenterol 2008;103:2570-2576.

115. Jizhong S, Qiaomin W, Chao W, Yanqing L. Corticotropinreleasing factor and Toll-like receptor gene expression is associated with low-grade inflammation in irritable bowel syndrome patients with depression. Gastroenterol Res Pract 2016;2016:7394924.

116. Seyedmirzaee S, Hayatbakhsh MM, Ahmadi B, et al. Serum immune biomarkers in irritable bowel syndrome. Clin Res Hepatol Gastroenterol 2016;40:631-637.

117. Schmulson M, Pulido-London D, Rodriguez O, et al. Lower serum IL-10 is an independent predictor of IBS among volunteers in Mexico. Am J Gastroenterol 2012;107:747-753.

118. Gao J. Correlation between anxiety-depression status and cytokines in diarrhea-predominant irritable bowel syndrome. Exp Ther Med 2013;6:93-96.

119. Bashashati M, Rezaei N, Shafieyoun A, et al. Cytokine imbalance in irritable bowel syndrome: a systematic review and metaanalysis. Neurogastroenterol Motil 2014;26:1036-1048.

120. Del Valle-Pinero AY, Martino AC, Taylor TJ, et al. Proinflammatory chemokine C-C motif ligand 16 (CCL-16) dysregulation in irritable bowel syndrome (IBS): a pilot study. Neurogastroenterol Motil 2011;23:1092-1097.

121. Belmonte L, Beutheu Youmba S, Bertiaux-Vandaële N, et al. Role of toll like receptors in irritable bowel syndrome: differential mucosal immune activation according to the disease subtype. PLoS One 2012;7:e42777.

122. Chen J, Zhang Y, Deng Z. Imbalanced shift of cytokine expression between $\mathrm{T}$ helper 1 and $\mathrm{T}$ helper 2 (Th1/Th2) in intestinal mucosa of patients with post-infectious irritable bowel syndrome. $B M C$ Gastroenterol 2012;12:91.

123. Macsharry J, O’Mahony L, Fanning A, et al. Mucosal cytokine imbalance in irritable bowel syndrome. Scand J Gastroenterol 2008;43:1467-1476.

124. Sundin J, Rangel I, Repsilber D, Brummer RJ. Cytokine response after stimulation with key commensal bacteria differ in postinfectious irritable bowel syndrome (PI-IBS) patients compared to healthy controls. PLoS One 2015;10:e134836.

125. Olivo-Diaz A, Romero-Valdovinos M, Gudiño-Ramirez A, et al. Findings related to IL-8 and IL-10 gene polymorphisms in a Mexican patient population with irritable bowel syndrome infected with Blastocystis. Parasitol Res 2012;111:487-491.

126. Barkhordari E, Rezaei N, Mahmoudi M, et al. T-helper 1, T-helper 2 , and T-regulatory cytokines gene polymorphisms in irritable bowel syndrome. Inflammation 2010;33:281-286.

127. Barkhordari E, Rezaei N, Ansaripour B, et al. Proinflammatory cytokine gene polymorphisms in irritable bowel syndrome. J Clin Immunol 2010;30:74-79.

128. Villani AC, Lemire M, Thabane M, et al. Genetic risk factors for post-infectious irritable bowel syndrome following a waterborne outbreak of gastroenteritis. Gastroenterology 2010;138:1502-1513.

129. Gonsalkorale WM, Perrey C, Pravica V, Whorwell PJ, Hutchinson IV. Interleukin 10 genotypes in irritable bowel syndrome: evidence for an inflammatory component? Gut 2003;52:91-93.

130. van der Veek PP, van den Berg M, de Kroon YE, Verspaget HW, Masclee AA. Role of tumor necrosis factor-alpha and interleukin-10 gene polymorphisms in irritable bowel syndrome. Am J Gastroenterol 2005;100:2510-2516.

131. Takeda K, Akira S. Toll-like receptors. Curr Protoc Immunol 2015;109:109:14.12.1-10.

132. Takeuchi O, Akira S. Pattern recognition receptors and inflammation. Cell 2010;140:805-820.

133. McKernan DP, Nolan A, Brint EK, et al. Toll-like receptor mRNA 
expression is selectively increased in the colonic mucosa of two animal models relevant to irritable bowel syndrome. PLoS One 2009;4:e8226.

134. Chen ZY, Zhang XW, Yu L, et al. Spinal toll-like receptor 4-mediated signalling pathway contributes to visceral hypersensitivity induced by neonatal colonic irritation in rats. Eur J Pain 2015;19:176-186.

135. Clarke G, McKernan DP, Gaszner G, Quigley EM, Cryan JF, Dinan TG. A distinct profile of tryptophan metabolism along the kynurenine pathway downstream of Toll-like receptor activation in irritable bowel syndrome. Front Pharmacol 2012;3:90.

136. Dlugosz A, Nowak P, D'Amato $M$, et al. Increased serum levels of lipopolysaccharide and antiflagellin antibodies in patients with diarrhea-predominant irritable bowel syndrome. Neurogastroenterol Motil 2015;27:1747-1754.

137. Brint EK, MacSharry J, Fanning A, Shanahan F, Quigley EM. Differential expression of toll-like receptors in patients with irritable bowel syndrome. Am J Gastroenterol 2011;106:329-336.

138. Koçak E, Akbal E, Köklü S, Ergül B, Can M. The colonic tissue levels of TLR2, TLR4 and nitric oxide in patients with irritable bowel syndrome. Intern Med 2016;55:1043-1048.

139. Lamkanfi M, Dixit VM. Mechanisms and functions of inflammasomes. Cell 2014;157:1013-1022.

140. Schroder K, Tschopp J. The inflammasomes. Cell 2010;140:821-832.

141. Ringel-Scaia VM, McDaniel DK, Allen IC. The Goldilocks conundrum: NLR inflammasome modulation of gastrointestinal inflammation during inflammatory bowel disease. Crit Rev Immunol 2016;36:283-314.

142. Liu JJ, Kay TM, Davis EM, et al. Epithelial cell extrusion zones observed on confocal laser endomicroscopy correlates with immunohistochemical staining of mucosal biopsy samples. Dig Dis Sci 2016;61:1895-1902.

143. Sun Y, Zhang M, Chen CC, et al. Stress-induced corticotropinreleasing hormone-mediated NLRP6 inflammasome inhibition and transmissible enteritis in mice. Gastroenterology 2013;144:1478-1487, 1487.e1-8.

144. Gu QY, Zhang J, Feng YC. Role of NLRP3 inflammasome in Bifidobacterium longum-regulated visceral hypersensitivity of postinfectious irritable bowel syndrome. Artif Cells Nanomed Biotechnol 2016;44:1933-1937.

145. Dunlop SP, Jenkins D, Neal KR, Spiller RC. Relative importance of enterochromaffin cell hyperplasia, anxiety, and depression in postinfectious IBS. Gastroenterology 2003;125:1651-1659.

146. Dunlop SP, Jenkins D, Spiller RC. Distinctive clinical, psychological, and histological features of postinfective irritable bowel syndrome. Am J Gastroenterol 2003;98:1578-1583.

147. Bhuiyan MR, Majumder TK, Raihan AA, Roy PK, Farha N, Kamal M. Histopathological alterations in post-infectious irritable bowel syndrome in Bangladeshi population. Mymensingh Med J 2010;19:275-281. 